\title{
EX-SITU AND IN-SITU SPECTROSCOPIC STUDIES OF THE PASSIVE FILM ON ALKALI AND ALKALINE EARTH METALS
IN NONAQUEOUS SOLVENTS
}

Final Report

March 1992

by

\author{
Kuilong Wang \\ Gary S. Chottiner \\ Pilar Herrera-Fierro \\ Daniel A. Scherson \\ Departments of Physics and Chemistry \\ Case Western Reserve University \\ Cleveland, Ohio 44106 \\ for \\ Exploratory Technology Research Program \\ Energy \& Environment Division \\ Lawrence Berkeley Laboratory \\ Berkeley, California 94720
}

This work was supported by the Assistant Secretary for Conservation and Renewable Energy, Office of Transportation Technologies, Electric and Hybrid Propulsion Division of the U.S. Department of Energy under Contract No. DE-AC03-76SF00098, Subcontract No. 4563910 with the Lawrence Berkeley Laboratory. 
TABLE OF CONTENTS

ABSTRACT $\ldots \ldots \ldots \ldots \ldots \ldots \ldots \ldots \ldots \ldots \ldots \ldots \ldots \ldots \ldots \ldots$

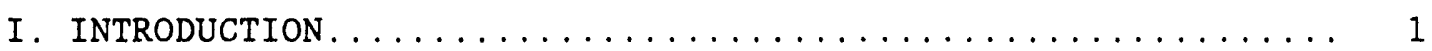

II. BONDING AND REACTIVITY OF CARBON DIOXIDE ON POTASSIUM

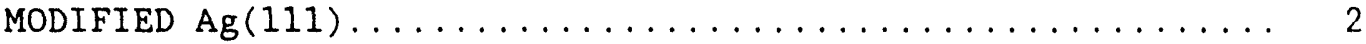

A. BACKGROUND. ........................... 2

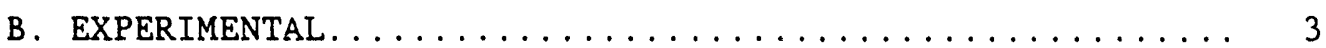

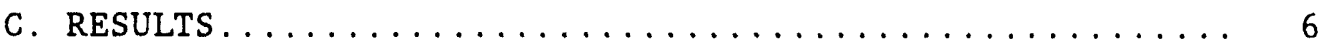

1. Temperature Programmed Desorption............. 6

2. Isotopic Labelling Experiments................ 11

3. X-ray Photoelectron Spectroscopy............... 12

4. High Resolution Electron Energy Loss Spectroscopy... 14

5 . On the effects of surface damage.............. 16

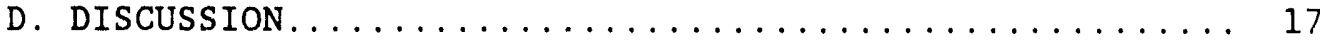

Model I. Adsorption of isolated $\mathrm{CO}_{2}$ molecules...... 17

Model II. Dissociation and reassociation of $\mathrm{CO}_{2} \ldots \ldots \ldots 17$

Model III. Dissociation of $\mathrm{CO}_{2}$ and further reaction of $\mathrm{CO}_{2}$ with the resulting fragments....... 19

Model IV. Association of Adsorbed, Activated $\mathrm{CO}_{2} \ldots \ldots 21$

E. CONCLUSIONS ........................... 22

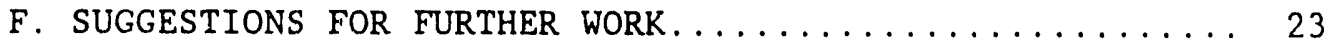

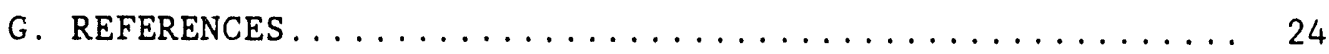

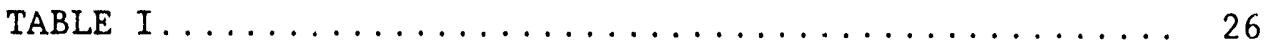

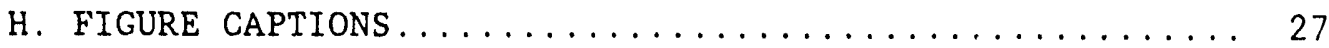




\section{ABSTRACT}

The adsorption of carbon dioxide on potassium-dosed $\mathrm{Ag}(111)$ has been investigated with temperature-programmed desorption (TPD), work function measurements, and Auger electron (AES), X-ray photoelectron (XPS), and high resolution electron energy loss (HREELS), spectroscopies. Unlike the behavior observed for other K-modified single-crystal metal surfaces, the TPD spectra of near-saturation coverages of $\mathrm{CO}_{2}$ on $\mathrm{K} / \mathrm{Ag}(111$ ) for $\mathrm{K}$ coverages in the range $0.13<\theta_{\mathrm{K}}<0.47$ (the close packed monolayer corresponds to $\theta_{\mathrm{K}}$ $=1 / 3$ ) exhibit a sharply defined $\mathrm{m} / \mathrm{e}=44$ peak at $796+/-6 \mathrm{~K}$ with no evidence for the desorption of $C O$ at any temperature. Similar TPD experiments involving mixtures of natural and 180 -labelled $\mathrm{CO}_{2}$ indicate that the oxygen atoms undergo partial scrambling, suggesting that the overall process cannot be represented in terms of a simple adsorption/desorption of $\mathrm{CO}_{2}$. The HREELS spectra of $\mathrm{CO}_{2}$-saturated $\mathrm{K} / \mathrm{Ag}$ (111) show, in addition to very minor features, a sharp peak at about $1480 \mathrm{~cm}-1$, and XPS spectra of the same interface display a C(1s) peak with a binding energy characteristic of an electron-rich carbon species. This information is consistent with the presence of a carbon-bound $C O$ species on the surface. Evidence against the complete dissociation of $\mathrm{CO}_{2}$ was obtained from TPD which failed to reveal features associated with carbonate (decomposition) expected to be formed via the reaction of $\mathrm{CO}_{2}$ and adsorbed 0 . On the basis of these results, it is proposed that $\mathrm{CO}_{2}$ on $\mathrm{K} / \mathrm{Ag}(111)$ binds through the carbon to the surface leading to the "partial" dissociation (or activation) of each $\mathrm{CO}_{2}$ molecule into adsorbed $\mathrm{CO}$ and 0 . Within this model, such adsorbed 0 would serve as a bridge between the carbon atoms of neighboring "activated" $\mathrm{CO}_{2}$ molecules, and therefore undergo exchange prior to or during thermal desorption.

Adventitious water or oxygen in the system and/or defect sites on the surface give rise to an additional $\mathrm{m} / \mathrm{e}=44 \mathrm{TPD}$ peak at a much higher temperature. The height of this new feature is increased significantly by pre-dosing the $\mathrm{K} / \mathrm{Ag}(111)$ surface with $\mathrm{O}_{2}$ or $\mathrm{H}_{2} \mathrm{O}$ at coverages as 1 ow as 0.05 L. The XPS spectra for these purposely contaminated surfaces reveal features very different than those observed in the absence of such impurities, but consistent with the presence of an ordinary form of carbonate. Ag(111) surfaces which had been damaged prior to $\mathrm{K}$ deposition and subsequent $\mathrm{CO}_{2}$ adsorption were found to yield significant amounts of co in the TPD spectra at lower temperatures. 


\section{INTRODUCTION}

The operation of lithium electrodes for battery applications relies on the presence of a film at the metal electrolyte interface which displays two essential characteristics: it provides a protective barrier that hinders the corrosion of the metal beneath and it serves as a medium for the conduction of $\mathrm{Li}^{+}$-ions. 1

Two main models have been described in the literature to account for the structure and properties of these passive films. The first is based on the formation of an inorganic surface layer in which ionic transport is described by solid electrolyte theory, ${ }^{2}$ whereas the second assumes that the film has both a compact and a porous layer with polymer-like characteristics. ${ }^{3}$

The main aim of this research project is to elucidate the structure and composition of alkali metal non-aqueous solvent passive films by using an array of in-situ and ex-situ spectroscopic techniques such as Fourier Transform Reflection Absorption Infrared Spectroscopy (FTIRRAS), Auger Electron and X-ray Photoelectron Spectroscopies (AES and XPS, respectively), and Temperature Programmed Desorption (TPD). The procedures developed in this group to gain insight into some of these issues involve vapor deposition of the alkali metal on top of a well-defined, clean inert substrate followed by dosing with the desired non-aqueous solvent. All of these operations are carried out under UHV conditions to avoid contamination. Preliminary measurements of this tylse involving ultrapurified propylene carbonate ( $P C$ ) indicated that this solvent undergoes spontaneous decomposition, yielding carbon dioxide as one of the principal products. In light of these observations, attention was focused on the nature of the reactions that occur between carbon dioxide and alkali metals. 
This report summarizes the results of experiments involving $\mathrm{CO}_{2}$ adsorption on vapor-deposited layers of potassium on $\mathrm{Ag}(111)$ single crystals. $\mathrm{CO}_{2}$ displays no affinity for silver (in the strict absence of adsorbed oxygen) and therefore it is especially suited in measurements of this type. Furthermore, unlike lithium, for which the work published in the literature is scarce, potassium layers have been widely studied on a variety of more reactive substrates, thus providing a good basis for comparison.

\section{BONDING AND REACTIVITY OF CAR ON DIOXIDE ON POTASSIUM-MODIFIED Ag(111)}

\section{A. BACKGROUND}

The activation of carbon dioxide represents an essential step in the synthesis of methanol and other valuable organic compounds from $\mathrm{H}_{2}-\mathrm{CO}-\mathrm{CO}_{2}$ mixtures. ${ }^{4}$ Ad-layers of alkali metals on various single-crystal metal substrates promote the binding of carbon dioxide.5-10 This process is believed to involve charge transfer from the modified surface to the adsorbate to generate an intermediate anionic species denoted as $\mathrm{CO}_{2}^{-\delta}$. For example, in the case of $\mathrm{CO}_{2}$ adsorption on $\mathrm{Pt}(111)$ for $\mathrm{K}$ coverages $\left(\theta_{\mathrm{K}}\right)$ in excess of a close-packed monolayer $\left(\theta_{\mathrm{K}}>1 / 3\right), 7,8 \mathrm{CO}_{2}{ }^{-}$undergoes disproportionation to yield carbon monoxide and carbonate. This conclusion was reached on the basis of Temperature Programmed Desorption (TPD) measurements for which the amount of CO (peak temperature, $T_{p}=640 \mathrm{~K}$ ) was found to be similar to that of $\mathrm{CO}_{2}\left(\mathrm{~T}_{\mathrm{p}}=674\right.$ and $\left.790 \mathrm{~K}\right)$ arising from the decomposition of carbonate. Further evidence in support of this view is provided by the HREELS spectra, which displayed features at $1440 \mathrm{~cm}^{-1}$ and $1600 \mathrm{~cm}^{-1}$, which are attributed to carbonate and $\mathrm{CO}$, respectively. HREELS spectra recorded as a function of temperature for Na-modified $\mathrm{Pd}(111)$ at submonolayer coverages ${ }^{9}$ have indicated that $\mathrm{CO}_{2}{ }^{-}$undergoes decomposition at temperatures close to $270 \mathrm{~K}$, which generates adsorbed carbon monoxide (and 
not carbonate) as the only detectable species. However, carbonate could be observed in those experiments at $\mathrm{Na}$ coverages above a monolayer. The presence of carbonate-like species on $\mathrm{K}$-dosed $\operatorname{Pd}(100)^{5}$ and $\operatorname{Rh}(111)^{6}$ surfaces has also been proposed on the basis of UPS and XPS results.

This report presents TPD, XPS, work function measurements, and HREELS data for the adsorption of $\mathrm{CO}_{2}$ on $\mathrm{K}$-dosed $\mathrm{Ag}(111)$. Carbon dioxide exhibits no affinity for bare $\mathrm{Ag}(111)$ and is thus particularly suited for these studies. The behavio: observed for the system examined in this investigation was found to be qualitatively different than that for other $\mathrm{K}$-modified single-crystal meta? surfaces. In particular, the TPD spectra of nearsaturation exposure of $\mathrm{CO}_{2}$ on $\mathrm{K} / \mathrm{Ag}(111)$, for $\mathrm{K}$ coverages in the range $0.13<$ $\theta_{\mathrm{K}}<0.47$, displayed (in the strict absence of water and oxygen) a sharply defined $\mathrm{m} / \mathrm{e}=44$ peak at about $796 \mathrm{~K}$. There were no detectable co peaks at any other temperature (except that originating from the cracking of $\mathrm{CO}_{2}$ in the mass spectrometer). The HREELS and XPS spectra of such $\mathrm{CO}_{2} / \mathrm{K} / \mathrm{Ag}(111)$ surfaces appeared to be consistent with the presence of carbon-bound co. However, carbon dioxide does not undergo complete dissociation into $\mathrm{CO}$ and $\mathrm{O}$ on these surfaces, as no carbonate formed via the reaction of $\mathrm{CO}_{2}$ and $\mathrm{O}$ was detected by TPD. Instead, TPD experiments involving coadsorption of naturally abundant and $180-1$ abelled $\mathrm{CO}_{2}$ indicate that some of the oxygens (derived from $\mathrm{CO}_{2}$ ) can undergo exchange prior to or during desorption, suggesting that $\mathrm{CO}_{2}$ associates (via oxygen bridges) on the surface.

\section{B. EXPERIMENTAL}

Most TPD measurements reported in this work were carried out with a LEED-AES-TPD-transfer system described elsewhere.11 The XPS spectra were collected with a custom Perkin Elmer LEED-AES-XPS-TPD multiprobe unit using a PHI 10-360 hemispherical electron energy analyzer with an extended lens. The X-ray source employing an Al anode was operated at $400 \mathrm{~W}$, and $55^{\circ}$ from 
the sample normal. The analyzer was aligned with the sample normal and run with a pass energy of $17.9 \mathrm{eV}$. The statistical treatment of the XPS data was performed with routines supplied by Perkin Elmer for their series 5000 XPS U1.1.s. The HREELS spectra were acquired with a system described in detail earlier. 12

$\mathrm{Ag}(111)$ specimens in the form of disks, $12.5 \mathrm{~mm}$ in diameter and about 3 mm thick, obtained from two different suppliers (Metron Corp., PA and Monocrystals Inc., $\mathrm{OH}$ ) were oriented to within 1 degree with Laue backdiffraction, polished with a series of alumina compounds down to $0.05 \mu \mathrm{m}$, and finally etched for a few seconds in a chromate bath. The crystals were mounted on a special copper holder using $\mathrm{Ta}$ tabs inserted into slots that were spark cut into the sides of the disk. An alumel-chromel thermocouple junction was wedged into another spark-cut hole on the side of the crystal. $\mathrm{Ar}^{+}$-sputtering/annealing cycles were performed to obtain sharp LEED patterns displaying six-fold symmetry and AES spectra showing only features characteristic of clean silver. The total pressure in the chamber during the experiments was in the range of $6.0 \times 10^{-11}$ to $3 \times 10^{-10}$ torr with a partial pressure of water slightly higher than $1.0 \times 10^{-11}$ Torr. The latter turned out to be an important factor as the surface chemistry of the supported $\mathrm{K} / \mathrm{CO}_{2}$ system was found to be very sensitive to the presence of coadsorbed water (or atomic oxygen) on the surface.

Potassium was vapor deposited on $\mathrm{Ag}(111)$ by resistive heating of SAES Getters sources. Within the limit of detectability of the AES (see Figure 1) and XPS spectrometers, the $\mathrm{K}$ layers were found to be free of impurities, provided the source had been properly degassed prior to the evaporations.

$\mathrm{Ag}(111)$ crystals covered by about a single monolayer of $\mathrm{K}$ yielded either $\sqrt{3} \times \sqrt{3} \mathrm{R} 30^{\circ}$ and/or $\mathrm{p}(2 \times 2)$ LEED patterns, depending on the amount of 
$\mathrm{K}$ and the substrate temperature. Similar patterns have been reported for $\mathrm{K} / \mathrm{Pt}(111)^{13}$ and $\mathrm{K} / \mathrm{Pd}(111) .14$ An array of more complicated patterns was observed while cooling the $\mathrm{K} / \mathrm{Ag}(111)$ specimens to $90 \mathrm{~K}$. These, however, were not studied in detail in this investigation. Changes in the LEED patterns have also been noticed upon warming $\mathrm{K} / \mathrm{Pd}(111) .14$

The AES signal corresponding to the strongly bound $\mathrm{K}$ monolayer was establjshed by first depositing a $\mathrm{K}$ layer, several monolayers thick at 150 $K$, and then monitoring the AES signal as the sample was heated. A plot of the $8 \mathrm{~K}$-AES signal versus temperature yielded a break at around $300 \mathrm{~K}$ (see Fi $\mathcal{E}_{\text {Gre }}$ 2). The $8 \mathrm{~K}$ in this case was calculated by dividing the peak-to-peak height of the $\mathrm{K}_{\text {LMM }}(252 \mathrm{eV})$ transition, as measured in the derivative mode, by the sum of the peak-to-peak heights of $\mathrm{K}$ and $\operatorname{AgMNN}_{\mathrm{N}}(351 \mathrm{eV})$ using sensitivity normalization factors 1 isted in the $\Phi$ Handbook. $15 \mathrm{~A}$ drop in the intensity of the relative K-AES signal at about the same temperature, associated with bulk potassium desorption, was recently reported by Liu et al. 8 for K-covered $\mathrm{Pt}(111)$. Hence, the K-AES signal of 20-25\% may be ascribed to the presence of a single, strongly bound monolayer of $k$ on $\mathrm{Ag}(111)$, which corresponds to a coverage of $\theta_{\mathrm{K}}=1 / 3$. The results of these measurements were consistent with plots of the work function as measured with a Kelvin probe versus the $K$ coverage determined from AES. In accordance with information available in the literature, 16,17 such curves showed a net change of $2.5 \mathrm{eV}$ vs bare $\mathrm{Ag}(111)$ at monolayer coverage and a clear maximum change of $2.7 \mathrm{eV}$ at about $\theta_{\mathrm{K}}=0.2$.

For the majority of the measurements described in this work, the actual $\mathrm{K}$ coverage was determined after dosing the $\mathrm{K} / \mathrm{Ag}(111)$ crystal with $\mathrm{CO}_{2}$. This made it possible to decrease the time of exposure of bare $\mathrm{K} / \mathrm{Ag}(111)$ to background gases in the chamber and thus reduce the extent of surface contamination. According to Liu et al. 8 the changes in the relative $\mathrm{K} / \mathrm{Pt}$ AES 
intensities observed before and after exposing $\theta_{\mathrm{K}}=0.51$ monolayers to about 20 Langmuirs of carbon dioxide are very small. This was verified for the case of $\mathrm{Ag}(1.11)$ by constructing calibration curves between the time the SAES source was operated at a constant current and the actual amount of $\mathrm{K}$ deposited on the surface as determined from AES. Once the source was found to behave in a reliable and reproducible fashion, the time involved in each $K$ deposition was used to establish the $K$ coverage, i.e. no AES were recorded either before or after $\mathrm{CO}_{2}$ exposure. This method was found to yield excellent agreement with that described above for coverages up to and slightly above one monolayer of $\mathrm{K}$, as evident from a quantitative comparison between the corresponding TPD spectra.

Unlike the very high reactivity observed for bare $\mathrm{K} / \mathrm{Ag}(111)$ surfaces, the spectral characteristics of freshly prepared $\mathrm{CO}_{2}$-saturated $\mathrm{K} / \mathrm{Ag}(111$ ) specimens were found to remain unchanged even after several hours of exposure to background gases in the UHV chamber.

Carbon dioxide (Research Grade, 99.9958) was obtained from Matheson, whereas ${ }^{13} \mathrm{C}^{16} \mathrm{O}$ (998 isotopic purity) and $\mathrm{C}^{18} \mathrm{O}_{2}$ (98\% isotopic purity) were purchased from Icon Services Inc. The actual composition of the isotopically labelled carbon dioxide, as assayed by leaking the gas into the main chamber under conditions identical to those used during the experiments, differed substantially from that provided by the supplier. Of the nominally $98 \%$ isotopically 0-18 labelled $\mathrm{CO}_{2}$, mass spectrometry indicated the presence of only $588 \mathrm{C}^{18} \mathrm{O}_{2} \quad(48 \mathrm{amu})$ and $32 \& \mathrm{C}^{18} 0^{16} \mathrm{O}$ (46 amu) with the rest being naturally ocurring material.

\section{RESULTS}

1. Temperature Programmed Desorption

The TPD spectra of $\mathrm{K}\left(\theta_{\mathrm{K}}=1 / 3\right) / \mathrm{Ag}(111)$ after saturation exposure of 
$\mathrm{CO}_{2}$ (see below) was characterized by two $\mathrm{m} / \mathrm{e}=44$ peaks at temperatures higher than $720 \mathrm{~K}$ (see Figure 3). These peaks will be referred to hereafter as $\alpha$ (low temperature) and $\beta$ (high temperature). The magnitude of the co $(m / e=28)$ peaks associated with the $m / e=44$ TPD features for $\alpha$ and $\beta$ was in excellent agreement with that found for the cracking of $\mathrm{CO}_{2}$ in the mass spectrometer as determined in independent experiments. No evidence for other CO peaks could be found at any other temperature. This indicates that within the sensitivity limits of the equipment, $\mathrm{CO}_{2}$ is the only source of CO detected in the mass spectrometer. * This behavior is at variance with that reported for other $\mathrm{K}$-dosed single-crystal metal surfaces, 5,6,8 for which large amounts of $\mathrm{CO}$ not originating from the cracking of desorbed $\mathrm{CO}_{2}$ nave been found in the TPD spectra.

The conditions required to achieve saturation coverage of $\mathrm{CO}_{2}$ were determined by monitoring the work function of the $\mathrm{K} / \mathrm{Ag}(111)$ surface while dosing at room temperature. As shown in Figure 4 (solid line), $\Phi$ varies linearly for exposures of $\mathrm{CO}_{2}$ up to $1 \mathrm{~L}$. As the exposure was continued, the rate of change of $\Phi$ decreased considerably to a much smaller and steady value at about $5 \mathrm{~L}$. The integrated areas under the $\mathrm{m} / \mathrm{e}-44$ peaks in the TPD spectra of $K\left(\theta_{K}-1 / 3\right) / A g(111)$ as a function of $\mathrm{CO}_{2}$ exposure (solid circles, Figure 4) also behave in a similar fashion, indicating that the $\mathrm{CO}_{2}$ has a rather high sticking coefficient at low coverages and reaches saturation at about $5 \mathrm{~L}$.

Except for variations in the relative heights of peaks $\alpha$ and $\beta$, identical results were obtained with at least three different $\mathrm{Ag}(111)$ specimens in experiments conducted over periods of months, with some of the

* The sensitivity limit is actually set by the presence of co originating from the cracking of $\mathrm{CO}_{2}$ and the inherent signal-to-noise associated with its detection. On this basis, the upper limit For the coverage of $C O$ on the surface may be set at 18 . 
runs yielding essentially undetectable $\beta$ peaks (see below).

A sizable reduction in the height of peak $\beta$ was observed when $\mathrm{K} / \mathrm{Ag}(111)$ surfaces were exposed to $\mathrm{CO}_{2}$ immediately after $\mathrm{K}$ deposition, without prior characterization with AES or LEED (see Curve A, Figure 5). This indicates that species derived from background gases in the chamber can change the intrinsic chemistry associated with the otherwise clean $\mathrm{CO}_{2} / \mathrm{Ag}(111)$ system. At least two observations lend support to this view:

i) Experiments in which the $\mathrm{K} / \mathrm{Ag}(111)$ surfaces were purposely exposed to background gases for periods of up to two hours before dosing with $\mathrm{CO}_{2}$, yielded a much more pronounced $\beta$ peak. In fact, for the longest background exposure (ca. $2 \mathrm{~h}$ ), this was the only peak detected.

ii) A careful search for other desorbing masses indicated the presence of a small $\mathrm{m} / \mathrm{e}=32$ feature associated with peak $\beta$ (see Curve B, Figure 3). For peak $\alpha$ the magnitude of the $\mathrm{m} / \mathrm{e}-32$ peak is in agreement with the $(\mathrm{m} / \mathrm{e}=32) /(\mathrm{m} / \mathrm{e}-44)$ ratio (ca. 1300) measured experimentally for pure $\mathrm{CO}_{2}$ gas. This clearly shows that the high-temperature feature is due to a different species, possibly richer in oxygen, than that responsible for peak $\alpha$.

The degree of reproducibility of the TPD measurements was assessed by repeating a specific experiment six times, keeping all conditions as similar as possible. For these measurements, $\mathrm{K}$ was deposited at -55 to $-60^{\circ} \mathrm{C}$ to a coverage of about one monolayer as determined by AES. The surface was then dosed with $10 \mathrm{~L}$ of $\mathrm{CO}_{2}$ (at the same temperature) by backfilling the chamber to $5 \times 10^{-8}$ torr for $200 \mathrm{~s}$. The $\mathrm{m} / \mathrm{e}=44 \mathrm{TPD}$ of such surfaces displayed features with peak temperatures, $T_{p}+/$ - standard deviation, at $796+/-6 \mathrm{~K}$ and $874+/-6 \mathrm{k}$ with a ratio of peak heights of $0.4+/-0.1$, respectively (see Figure 3). For the six independent experiments involved in this series the sums of areas under the two peaks yielded values of standard 
deviation/average of about 48 .

A series of TPD experiments were conducted for $\theta_{K} \leq 1 / 3$ and saturation exposure of $\mathrm{CO}_{2}$. Unlike the behavior observed for peak $\alpha$, for which the peak area was found to be proportional to $\theta_{K}$, the area of peak $\beta$ reached a maximum for very small values of $\theta_{\mathrm{K}}$. A plausible explanation for this effect may be found in the presence of a small fraction of defect sites with a much higher affinity for $\mathrm{K}$ and/or $\mathrm{CO}_{2}$ than that of the sites responsible for peak $\alpha$. The temperature at the peak maximum $T_{i}(i=\alpha$ or $\beta$ ) for peak $\alpha$ was found to increase linearly with $\theta_{K}$, which can occur for zeroth-order desorption or a higher order process involving coverage-dependent energies and/or pre-exponential factors. In contrast, the values of $\mathrm{T}_{\beta}$ are independent of $\theta_{\mathrm{K}}$ (see Figure 6), as for simple first-order desorption. This clearly shows that peaks $\alpha$ and $\beta$ are associated with very different chemical species.

A strong indication that the peak $\beta$ corresponds to the presence of carbonate was obtained from experiments in which 0.5 to $1 \mathrm{~L}$ of water was adsurbed on $\mathrm{K}\left(\theta_{\mathrm{K}} \leq 1 / 3\right) / \mathrm{Ag}(111)$ prior to dosing the surface with $\mathrm{CO}_{2}$. As shown in Figure 7 , the TPD spectra in this case was largely dominated by peak $\beta\left(\mathrm{T}_{\beta}=902 \mathrm{~K}\right)$ for which the area was essentially identical to the sum of $\alpha$ and $\beta$ in the absence of intentionally added water These results are in close agreement with those reported by Blass et a1.18 who prepared surface carbonate by coadsorption of $\mathrm{KOH}$ (formed by direct coadsorption of $\mathrm{K}$ and $\mathrm{D}_{2} \mathrm{O}$ ) and $\mathrm{CO}_{2}$. Also, in accordance with that work, is the fact that no water peak could be detected indicating that any remnant of this species dissociates or desorbs at temperatures below those at which the TPD is initiated. Some indication of non-stoichiometry of the carbonate species produced by the coadsorption of $\mathrm{K}$ and $\mathrm{CO}_{2}$, may be found in the lower amount of $\mathrm{O}_{2}$ observed in the TPD in Figure 3 compared to the $\mathrm{K} /$ water $/ \mathrm{CO}_{2}$ 
coadsorption experiments (see Figure 7 or Blass et al.). It may be noted that the decomposition temperature of (bulk) $\mathrm{K}_{2} \mathrm{CO}_{3}(1064 \mathrm{~K}$ ) is higher than that for of other (bulk) alkali carbonates, e.g. $\mathrm{Cs}_{2} \mathrm{CO}_{3}(883 \mathrm{~K})$ and $\mathrm{Li}_{2} \mathrm{CO}_{3}$ $(723 \mathrm{~K}) .19$

The possible involvement of $\mathrm{CO}$ (the largest impurity in the background gases besides hydrogen) in the adsorption/reaction pathway of $\mathrm{CO}_{2}$ on $\mathrm{K} / \mathrm{Ag}(111)$ was also examined. As noted by other authors, $\mathrm{CO}$ exhibits no affinity for $\mathrm{K} / \mathrm{Ag}(111)$ at temperatures as low as $100 \mathrm{~K} .20$ In fact the very small amount of $\mathrm{CO}_{2}$ that desorbed after long $\mathrm{CO}$ exposures could be traced to the $\mathrm{CO}_{2}$ present in the chamber during $\mathrm{CO}$ dosing, arising most probably from desorption from the walls of the doser and/or the chamber and the ion pump. Also noteworthy is the fact that $\mathrm{CO}$ exhibits no affinity for bare $\mathrm{Ag}(111)$ in the temperature range used in this work.

No exchange was found between a reacted $\mathrm{CO}_{2} / \mathrm{K} / \mathrm{Ag}(111)$ surface with $\mathrm{CO}$ using $5 \mathrm{~L}$ of ${ }^{13} \mathrm{CO}$ as a probe. Interesting results were obtained, however, for a freshly prepared $\mathrm{K} / \mathrm{Ag}(111)$ surface exposed to an equimolar mixture of ${ }^{13} \mathrm{CO}$ and $\mathrm{CO}_{2}$, for which the TPD revealed $\alpha$ and $\beta$ peaks with $\mathrm{m} / \mathrm{e}-45$, and with relative integrated ratios inverse of those for $\mathrm{m} / \mathrm{e}=44$ (see Figure 8). An analysis of the gas mixture (prior to the actual exposure) indicated the presence of ${ }^{13} \mathrm{C}$-labelled $\mathrm{CO}_{2}((\mathrm{~m} / \mathrm{e}=45):(\mathrm{m} / \mathrm{e}-44)=2.38)$. This is most likely due to exchange reactions on the walls of the doser, chamber, or the collimator (prior to the actual surface exposure). Within experimental error, the ratio of $\mathrm{m} / \mathrm{e}=45$ to $\mathrm{m} / \mathrm{e}=44$ for peak $\alpha$ in the TPD spectra is very close (ca. 2.88) to that observed in the gas mixture. On this basis, this feature originates exclusively from (K-promoted) adsorbed $\mathrm{CO}_{2}$. In contrast, the ratio $(\mathrm{m} / \mathrm{e}=45 \mathrm{~m} / \mathrm{e}-44)$ for peak $\beta$ was found to be much larger, indicating that ${ }^{13} \mathrm{CO}$ is involved in the reaction pathway that 
produces the carbonate-like species.

The experiments at $\mathrm{K}$-coverages in excess of a monolayer yielded qualitatively similar results to those at the lower coverages, i.e. a prominent $\alpha$-peak with a much smaller $\beta$ peak originating in our view from adventitious oxygen impurities. From these findings, and given that the main thrust of the work was focused on the characterization and identification of what we regard as the new species (peak $\alpha$ ), no systematic studies of this system for large K-coverages were pursued.

The addition of $0.5 \mathrm{~L}$ of oxygen on $\mathrm{K} / \mathrm{Ag}(111)$ prior to $\mathrm{CO}_{2}$ exposure yielded only peak $\beta$ at a slightly higher temperature (see Fig. 9). In contrast to the water coadsorption experiments, a new m/e $=44$ peak with an area an order of magnitude smaller than that of peak $\beta$ with 2 corresponding $\mathrm{O}_{2}$ component could be observed close to $590 \mathrm{~K}$, a temperature much lower than that at which peak $\alpha$ is observed. A form of surface carbonate that is distinct from species $\beta$ in this work has been proposed by Campbel121 to explain the presence of $\mathrm{m} / \mathrm{e}=44 \mathrm{TPD}$ peaks at $440 \mathrm{~K}$, in the case of $\mathrm{CO}_{2}$ exposure to $\mathrm{p}(4 \times 4)-0$ ad-layers on $\mathrm{Ag}(111)$ at room temperature. It thus seems reasonable to assume that the features observed in this work for oxygen predosed $\mathrm{K} / \mathrm{Ag}(111)$ at $590 \mathrm{~K}$ may also originate from a similar type of surface species.

\section{Isotopic Labelling Experiments}

Measurements similar to those described in the previous section were conducted by employing mixtures of natural and isotopically labelled ( $\left.{ }^{18} \mathrm{O}\right)$ carbon dioxide to gain insight into possible adsorbate-adsorbate interactions. An analysis of the TPD peaks for three different isotopic mixtures, namely, (m/e 44:46:48) I. 10:32:58; II. 54:32:14; III. 89:7:3, indicated a decrease in the $\mathrm{m} / \mathrm{e}=48$ species and an increase in the $\mathrm{m} / \mathrm{e}=46$ species with respect to their original values (see Table I). This strongly 
suggests that a certain degree of isotopic scrambling of adsorbed $\mathrm{CO}_{2}$ occurs on the alkali-metal modified surface. These results may be regarded as largely qualitative, however, as large deviations were found between the "total" amount of 160 and 180 before and after TPD. This is clearly evident by the fact that $\mathrm{m} / \mathrm{e}=44$ is higher than that predicted by a complete statistical scrambling. Such discrepancies may be derived fron a possible exchange of $\mathrm{CO}_{2}$ on the walls of the chamber or the collimator. Some support for this view was obtained by experiments (not involving the $\mathrm{Ag}(111$ ) crystal) in which the composition of the $\mathrm{CO}_{2}$ gas was monitored after exposing the chamber to isotopically labelled $\mathrm{CO}_{2}$ (followed by complete evacuation) and then reexposed to natural $\mathrm{CO}_{2}$. A small, but nevertheless noticeable $m / e=46$ peak could be detected during the second dosing, indicating an exchange reaction between material reacted during the first and second exposures. Although this factor complicates a quantitative analysis of the data, the variations in the isotopic ratios listed in Table I are too large to be accounted for by wall effects alone. The scrambling of oxygen could arise from any of a number of surface processes, which are considered in detail in the Discussion Section.

\section{X-ray Photoelectron Spectroscopy}

The XPS spectra of $10 \mathrm{~L} \mathrm{CO} 2 / \mathrm{K}\left(\theta_{\mathrm{K}}=1 / 3\right) / \mathrm{Ag}(111)$ prepared by $\mathrm{CO}_{2}$ dosing immediately after $\mathrm{K}$ evaporation at a temperature of $263 \mathrm{~K}$ displayed a major and a minor $\mathrm{C}(1 \mathrm{~s})$ peak at 284.0 and $289.0 \mathrm{eV}$, respectively. Additional features due to $X$-ray satellites of the main $K$ peak at higher binding energies (see Panel Al in Figure 10) were also observed. The area of the $284.0 \mathrm{eV}$ peak is about five times larger than that of the $289.0 \mathrm{eV}$ peak. This value is similar to that observed for the ratios of the areas of peaks $\alpha$ and $\beta$ from TPD. A C(ls) peak at $289.5 \mathrm{eV}$ was reported by Blass et al. 18 
for $\mathrm{KOD} / \mathrm{K}_{2} \mathrm{CO}_{3}$ samples, indicating that peak $\beta$ is associated with a carbonate species. $C(1 s)$ peaks with binding energies as low as those found in this work for specimens displaying predominantly peak $\alpha$ were reported for CO adsorbed on $\mathrm{K}$-covered-Fe(100), $-\mathrm{Ni}(100)$ and $-\mathrm{Cu}(100) .22$ This phenomenon has been ascribed to an increase in the occupation of the CO $2 \pi$ orbital and an interaction between the CO $1 \pi$ orjital and the $K 4 \mathrm{~s}$ state. Somewhat surprisingly, the $O(1 s)$ XPS spectra for this specimen (see Panel A2 in Figure 10) displayed a single peak at about $531-532 \mathrm{eV}$. The total $\mathrm{C}$ to 0 elemental ratios, as calculated based on the sensitivity factors for the analyzer used in these experiments, was about $1: 1.6$, which is close to the $1: 2$ ratio expected for $\mathrm{CO}_{2}$.

The unique $\mathrm{C}(1 \mathrm{~s})$ XPS species observed for $\mathrm{CO}_{2}$ on $\mathrm{K} / \mathrm{Ag}(111)$ disappeared upon adsorption of dioxygen (see Panel B1 in Figure 10) or water (see Panel $\mathrm{Cl}$ in the same figure) on the $\mathrm{K} / \mathrm{Ag}(111)$ surface prior to $\mathrm{CO}_{2}$ dosing. The peaks in the region between 280 and $287 \mathrm{eV}$, which are labelled by the stars correspond to K-satellites. As shown in the figure, the $C(1 s)$ spectra consist of a peak at $288.9 \mathrm{eV}$ for $\mathrm{O}_{2}(289.9 \mathrm{eV}$ for water) and a much smaller shoulder at slightly lower energy for the case of water. These data suggest that the adsorbed species associajed with peaks $\alpha(C(1 \mathrm{~s})$ at $284 \mathrm{eV})$ and $\beta$ $(C(1 \mathrm{~s})$ at $289 \mathrm{eV})$ are bound to the surface via carbon and oxygen, respectively.

Unlike the differences observed in the C(1s) XPS spectra, the O(1s) XPS spectra for $\mathrm{CO}_{2}$ adsorbed on $\mathrm{K} / \mathrm{Ag}(111)$ surfaces with and without pre-dosed oxygen were similar and largely dominated by the feature at 531-532 eV (see Panels A2 and B2 in Figure 10). Noteworthy, however, is the presence of a significant second peak at $535.8 \mathrm{eV}$ for the water-contaminated surface. This peak occurs at a much higher binding energy than that observed for $\mathrm{KOH}$ formed by exposure of multilayer $\mathrm{K}$-covered $\mathrm{Ag}(111)$ to water. ${ }^{18}$ More work 
will be necessary to elucidate the origin of this feature.

\section{High Resolution Electron Energy Loss Spectroscopy*}

Figure 11 shows a HREELS spectrum for $\theta_{\mathrm{K}}=0.13$, which was obtained immediately after a saturation dose of $\mathrm{CO}_{2}$, a procedure which gave $\mathrm{CO}_{2}$ desorption in the low-temperature $\alpha$ region only. The spectrum is dominated by a peak at $1480 \mathrm{~cm}^{-1}$, with a shoulder near $1680 \mathrm{~cm}^{-1}$ and a very small but reproducible shoulder around $1370 \mathrm{~cm}^{-1}$. A sizable but barely resolved feature appearing near $180 \mathrm{~cm}^{-1}$ increased in intensity with increasirg potassium coverage, and is due to a $\mathrm{Ag}-\mathrm{K}$ stretch. As this mode grew stronger, so did the intensity of the $1680 \mathrm{~cm}^{-1}$ shoulder, suggesting that this latter feature is due at least in part to a combination band of the $\mathrm{Ag}$ $\mathrm{K}$ stretch and the main peak at $1480 \mathrm{~cm}^{-1}$. Additional weak features were seen near 500,860 , and $2960 \mathrm{~cm}^{-1}$.

Although the spectrum in Figure 11 was obtained by dosing with $\mathrm{CO}_{2}$ under conditions which yielded no mass 28 in TPD beyond that expected from the cracking pattern of $\mathrm{CO}_{2}$, the major features of the data show a strikingly close resemblance to published HREELS spectra for low coverages of $\mathrm{CO}$ added to submonolayer $\mathrm{K}$ on $\mathrm{Ru}(0001) .23$ Points of agreement between the spectra include the frequency of the main mode, the small mode near $500 \mathrm{~cm}^{-}$ 1 , and the frequencies and shape of the "overtone/double loss" region at around $2960 \mathrm{~cm}^{-1}$. De Paola et al. attributed the very low C-0 stretching frequency and the low intensity of the $M-C$ mode near $600 \mathrm{~cm}^{-1}$ to side-on bonding of the $\mathrm{CO}$, with the $\mathrm{C}-\mathrm{O}$ axis either horizontal or tilted strongly from the normal to the surface. Since the surprisingly low $C(1 s)$ XPS binding energy $(284 \mathrm{eV})$ for $\mathrm{CO}_{2} / \mathrm{K} / \mathrm{Ag}(111)$ was also observed for $\mathrm{CO}$ coadsorbed with *...............

* The HREELS spectra were acquired by Frederick $T$. Wagner and Thomas $E$. Moylan at General Motors Research Laboratories, Physical Chemistry Department, Warren, Michigan 48090-9055. 
alkali metals, the HREELS and XPS spectroscopies together suggest the possibility that the $\alpha-\mathrm{CO}_{2}$ desorption peak arises from the reaction of adsorbed $\mathrm{CO}$ and 0 (see below). A double-loss feature at $2960 \mathrm{~cm}^{-1}$ and a weak mode at $500 \mathrm{~cm}^{-1}$ were also seen for $\mathrm{CO} / \mathrm{K} / \mathrm{Ru}(0001)$, with the latter ascribed to a Ru-O stretch arising from the dissociation of a small amount of $\mathrm{CO}$ on defects sites. One might expect a metal-oxygen stretch in the present experiment if $\mathrm{CO}_{2}$ is dissociating to produce a $\mathrm{CO}$ species. If the major $1480 \mathrm{~cm}^{-1}$ mode for $\mathrm{CO}_{2} / \mathrm{K} / \mathrm{Ag}(111)$ is attributed solely to adsorbed $\mathrm{CO}$, then the weak but reproducible modes at 860 and $1080 \mathrm{~cm}^{-1}$ would have to be ascribed to $\mathrm{K}_{\mathrm{x}} \mathrm{O}_{\mathrm{y}}$ modes for species with surprisingly high $\mathrm{O} / \mathrm{K}$ ratios as suggested in Ref. 8 .

Since the assignment of the $\alpha$ state as coadsorbed $C O$ and 0 does not correlate with the TPD data, it appears wise to consider whether or not the HREELS data might be consistent with the presence of other species on the surface. In particular, the data for oxygen isotope scrambling raise the possibility that the $\alpha$ state is a form of carbonate species, albeit one chemically distinct from the more typical carbonate species of the $\beta$ state. White and coworkers ${ }^{8}$ reported a single dominant peak at a similar energy to the $1480 \mathrm{~cm}^{-1}$ seen here after heating $\mathrm{K} / \mathrm{CO}_{2} / \mathrm{Pt}(111)$ above $700 \mathrm{~K}$. They assigned this HREELS peak to a carbonate species, although in the same work modes near $1450 \mathrm{~cm}^{-1}$ were assigned to the adsorption of background co stabilized by the presence of oxygen. For comparison, bulk ionic carbonates give two strong infrared adsorption bands at $1410-1450 \mathrm{~cm}^{-1}$ (C-0 stretch) and $840-880 \mathrm{~cm}^{-1}\left(\mathrm{CO}_{3}\right.$ out-of-plane deformation). 24 A weak feature appeared reproducibly near $860 \mathrm{~cm}^{-1}$ for $\mathrm{CO}_{2} / \mathrm{K} / \mathrm{Ag}(111)$, suggesting the spectrum in Figure 11 resembles that of a bulk ionic carbonate. However, upon coordination of a free carbonate ion to another atom to form a metal 
carbonato complex or organic carbonate (or presumably, a surface adsorbed species), the C-O stretch is split into symmetric and asymmetric modes near 1370 and $1580 \mathrm{~cm}^{-1}$ for unidentate carbonato complexes and 1610 and $1280 \mathrm{~cm}^{-1}$ for bidentate complexes. More complex HREELS spectra showing these split modes have been reported for adsorbed carbonate species formed in the reaction of oxygen and $\mathrm{CO}_{2}$ on $\mathrm{Ag}(110), 25$ though more recent data suggest that the carbonate species 1 ie in a plane parallel to the surface. 26 While the frequency fit between the one strong mode seen in this work and one of the modes of a unidentate carbonate is good, it is difficult to rationalize (based on selection rules) why the $1370 \mathrm{~cm}^{-1}$ mode from a unidentate carbonate should be so weak (if it is visible at all) in the spectrum in Figure 11. Given the notorious lack of predictability of relative mode intensities in HREELS, the carbonate interpretation cannot be completely rejected even for the main peak. However, the uncanny resemblance to published HRRELS spectra of CO adsorbed on surfaces modified by alkalimetal, and the agreement in the $C(1 s)$ XPS data, make a Co rather than a carbonate species more consistent with the available spectroscopic data.

\section{Effects of surface damage}

$\mathrm{Ag}(111)$ surfaces that are annealed repeatedly (ca. 20 times) at very high temperatures develop white (or cloudy) areas, as judged by visual inspection at appropriate angles of incidence. Analysis of these surfaces by optical microscopy and scanning Auger microscopy showed structural features such as pits and other asperities with characteristic dimensions of about 25 $\mu$, but no evidence of surface impurities. The presence of surface roughening did not noticeably diminish the quality of the LEED patterns (although it increased the diffuse background by an unquantified amount), but the surface chemistry associated with the $\mathrm{CO}_{2} / \mathrm{K} / \mathrm{Ag}(111)$ system was drastically changed. In particular, a new $\mathrm{CO}$ peak with no $\mathrm{CO}_{2}$ counterpart was detected in the TPD 
spectra in the temperature range between 680 and $740 \mathrm{~K}$, in addition to poorly defined $\alpha$ and $\beta$ peaks (see Figure 12). This clearly indicates that the $\mathrm{CO}_{2}$ activation pathway(s) is mcdified by microtopography and $\backslash$ or concentration of random defects in the underlying substrate.

\section{DISCUSSION}

The process responsible for peak $\alpha$ in the TPD spectra of $\mathrm{CO}_{2}$ adsorbed on $\mathrm{K} / \mathrm{Ag}(111)$ must be consistent with the lack of a CO peak and the scrambling of oxygen, the prominent HREELS peak at $1480 \mathrm{~cm}^{-1}$, and the low binding energy $C(1 s)$ XPS peak. A number of possible models have been considered to explain these data, including adsorption of isolated $\mathrm{CO}_{2}$ molecules, dissociation and reassociation of adsorbed $\mathrm{CO}_{2}$, dissociation of $\mathrm{CO}_{2}$ and further reaction of $\mathrm{CO}_{2}$ with the resulting fragments, and association of adsorbed, activated $\mathrm{CO}_{2}$. These are discussed in detail below.

Model I. Adsorption of 1solated $\mathrm{CO}_{2}$ molecules.

Although the TPD spectra indicate that $\mathrm{CO}_{2}$ is the only desorbing species, the fact that the isotopic mixing experiments show some scrambling is not consistent with the adsorption of isolated $\mathrm{CO}_{2}$ molecules. Therefore a process represented by:

$$
{ }^{\star} \mathrm{OCO} \text { (gas) } \ldots . . . . . .>{ }^{*} \mathrm{OCO}^{\delta} \text { (ads) } \ldots . . . .{ }^{*} \mathrm{OCO} \text { (gas) }
$$

where * denotes a specific oxygen atom, cannot be responsible for the observed phenomenon. Furthermore, the $\mathrm{CO}_{2}{ }^{\delta-}$ species produced by coadsorption of $\mathrm{CO}_{2}$ and $\mathrm{K}$ on $\mathrm{Pt}(111)$ has been shown to exhibit three peaks in the HREELS spectra at 780,1220 , and $1520 \mathrm{~cm}^{-1}$ which is very different than the essentially single-peaked HREELS spectra observed in this work.

Model II. Dissoclation and re-association of $\mathrm{CO}_{2}$.

Besides model I, the simplest mechanism that might be envisioned is the dissociation and re-association of carbon dioxide on the surface, i.e. 


$$
\begin{aligned}
& \mathrm{K} / \mathrm{Ag}(111) \quad \text { TPD } \\
& \mathrm{CO}_{2} \text { (gas) } \ldots . . . .-\mathrm{CO} \text { (ads) }+\mathrm{O} \text { (ads) } . . . . .-\mathrm{CO}_{2} \text { (gas) }
\end{aligned}
$$

The surface dissociation of $\mathrm{CO}_{2}$ into $\mathrm{CO}$ (ads) and $\mathrm{O}$ (ads) was proposed for Na-modified $\mathrm{Pd}(111)^{9}$ and $\mathrm{K}$-modified $\mathrm{Pt}(111)^{8}$ at submonolayer coverages on the basis of HREELS 8,9 and angle-resolved ultraviolet photoemission spectroscopy (ARUPS).27 The presence of adsorbed atomic oxygen (a species capable of migrating into the bulk metal) on $\mathrm{Na} / \mathrm{Pd}(111),{ }^{9}$ however, could not be detected with either of these techniques.

As noted in Sections 3 and 4 , both the XPS and HREELS spectra are consistent with the presence of adsorbed $\mathrm{CO}$ on the surface. One of the major difficulties with this model, however, is the fact that $\mathrm{O}$ (ads) on $\mathrm{K} / \mathrm{Ag}(111$ ) (see Section 1) reacts with $\mathrm{CO}_{2}$ to form a carbonate species (peak $\beta$ ). The same surface reaction was reported for $\mathrm{K} / \mathrm{Pt}(111)$ and $\mathrm{K} / \mathrm{Ag}(111)$ for $\mathrm{high} \theta_{\mathrm{K}}$ values by Liu et a1. ${ }^{8}$ They proposed that, in the case of $K / \operatorname{Pt}(111)$, the cleavage of $C O$ to generate $O$ (ads) is an essential intermediate step for the formation of a surface carbonate species.

Further insight into the interactions between $O$ (ads) and $C O$ was gained by exposing to $5 \mathrm{~L}$ of ${ }^{13} \mathrm{CO}$ a $\mathrm{K} / \mathrm{Ag}(111)$ surface that had been predosed with The TPD spectra displayed a prominent $\mathrm{m} / \mathrm{e}-45$ at temperatures associated with peak $\beta$ and no detectable peak $\alpha$. This implies that 0 (adsorbed) does not combine with $C O$ to form the species associated with peak $\alpha$ at the exposure of $\mathrm{O}_{2}$ used.

As noted in Section 1 , the (simultaneous) coadsorption of $\mathrm{CO}_{2}$ and ${ }^{13} \mathrm{CO}$ failed to produce a m/e $=45 \alpha$-peak in the TPD spectra. Since CO, which is irreversibly adsorbed on certain metal surfaces, can exchange with $c 0$ in the gas phase, as illustrated by Yamada and Tamaru for polycrystalline Rh foils, 28 the results obtained in this work suggest that the species present 
on $\mathrm{CO}_{2} / \mathrm{K} / \mathrm{Ag}(111)$ surfaces is different from isolated $\mathrm{CO}$ (ads).

A possible pathway that is consistent with the data would involve a recombination of the adsorbed $C O$ with oxygen in the lattice (originating from the dissociation of $\mathrm{CO}_{2}$ ) via thermally-induced segregation. ${ }^{9}$ This mechanism would require a faster migration step than the reaction between $\mathrm{CO}_{2}$ and adsorbed oxygen (a process that is known to generate carbonate as the product), and for oxygen segregation to occur prior to co desorption. Both of these possibilities, however, seem highly unlikely.

Many of the arguments against this specific model can, in principle, be circumvented by postulating that the affinity of $\mathrm{CO}_{2}$ for $\mathrm{O}$ (adsorbed) is drastically reduced by the presence of a stabilizing neighboring $c 0$ (ads) species, a postulate differing only in degree from that of Model IV given below.

Model III. Dissociation of $\mathrm{CO}_{2}$ and further reaction of $\mathrm{CO}_{2}$ with the resulting fragments.

Our studies and those of white and co-workers 20 showed that co displays essentially no affinity for $K, K$-modified silver, and bare silver surfaces. Hence, the possibility exists that adsorbed $\mathrm{CO}_{2}$ dissociates on the surface to yield adsorbed carbonate species as the product via the reaction below:

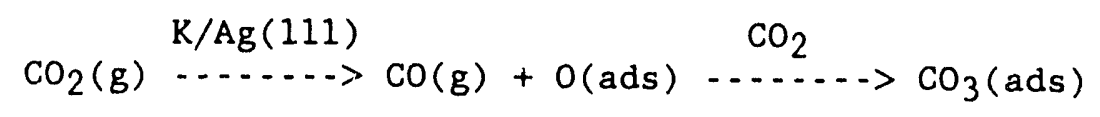

The reaction pathway indicates co undergoes desorption to leave atomic oxygen on the surface which then reacts with another carbon dioxide molecule to yield the carbonate species. The virtues of this mechanism are two-fold:

i) accounts for the presence of a single $\mathrm{CO}_{2}$ peak in the TPD spectra originating from thermal decomposition of the species that are responsible for peak $\alpha$.

ii) explains the isotopic scrambling results by simply assuming that $O$ (ads) 
(in the carbonate) becomes equivalent to at least one of the oxygens originating from the second $\mathrm{CO}_{2}$, and

iii) with the possible exception of the 0-C-O scissor mode, the HREELS spectra are to some extent consistent with the presence of an isolated carbonate species bound to the surface.

Several factors, however, argue against this model. In particular, the experiments in which oxygen was adsorbed onto $\mathrm{K} / \mathrm{Ag}(111)$ prior to exposure to $\mathrm{CO}_{2}$ yielded the conventional type of carbonate species for which the desorption temperature is much higher than that of peak $\alpha$. Another possibility is that the species formed is a non-conventional type of carbonate with a much lower decomposition temperature. In this model only $\mathrm{CO}_{2}$ is thermally desorbed, leaving atomic oxygen on the surface that, in principle, undergoes desorption at a much higher temperature. Careful inspection of the peak in the $\mathrm{m} / \mathrm{e}-32$ TPD spectra indicates that for surfaces for which peak $\alpha$ is at least an order of magnitude larger than peak $\beta$, the amount of dioxygen did not exceed that expected from the decomposition of the genuine surface carbonate associated with peak $\beta$.

Attempts were made to measure the gas-phase co that would be generated by the mechanism in Eq. (2). For these experiments, a freshly prepared $\mathrm{K} / \mathrm{Ag}(111)$ surface was placed in front of the collimator of the mass spectrometer prior to and during dosing with $\mathrm{CO}_{2}$. If every $\mathrm{CO}_{2}$ molecule reaching the surface reacted according to the mechanism in Eq. (3), the CO produced should result in a two-fold increase in the CO signal over the background, which is due to the cracking of $\mathrm{CO}_{2}$ during the dosing. No such increase was detected making this possibility very unlikely. It may thus be concluded from this analysis that if peak $\alpha$ is a form of a carbonate species its stoichiometry would differ considerably from that of $\mathrm{CO}_{3}$. 
Model IV. Assoclation of Adsorbed, Activated $\mathrm{CO}_{2}$.

The isotopic-labelling experiments indicate a substantial fraction of the oxygen atoms undergo scrambling to yield $\mathrm{C}^{18} \mathrm{O}_{2}: \mathrm{C}^{16} \mathrm{O}^{180} \mathrm{O}: \mathrm{C}^{16} \mathrm{O}_{2}$ ratios quite different than those in the original mixture. As noted earlier, the other TPD evidence does not allow for the formation of a regular (isolated) type of $O$ (ads), such as that involved in Model II. Hence, the simplest mechanism that could give rise to this phenomenon is activation involving a partial dissociation of adsorbed $\mathrm{CO}_{2}$ to yield $\mathrm{CO}$ (ads)-like moeities linked by the remaining oxygen atoms to form oligomeric species. This then provides conditions for a fraction of the oxygen atoms to undergo exchange prior to or upon desorption as the TPD experiments involving 0 -labelled $\mathrm{CO}_{2}$ indicate. The individual, partially dissociated $\mathrm{CO}_{2}$ units in the oligomer, as indicated by the low binding energy of the $C(1 s)$ peak characteristic of contaminant-free $\mathrm{CO}_{2} / \mathrm{K} / \mathrm{Ag}(111)$ system, would be bound through the carbon to the surface. A schematic diagram of such oligomeric species is shown in Figure 13, in which the solid lines represent $\mathrm{C}-\mathrm{O}$ bonds subtending a small, rather than a large, angle with respect to the surface normal; whereas the dashed lines denote $\mathrm{C}-\mathrm{O}$ bonds that are mostly parallel to the surface. Although not explicitly indicated, such oligomers could also form closedloop structures or rings.

Regardless of the detailed nature of this newly identified species, the different reaction pathways of $\mathrm{CO}_{2}$ on $\mathrm{K}$-modified $\mathrm{Ag}(111)$ and $\mathrm{K} / \mathrm{Pt}(111)^{7,8}$ (and also $\mathrm{Pd}^{5}, 9$ and $\mathrm{Rh}^{6}$ ) may be ascribed to the much weaker affinity of $\mathrm{Ag}(111)$ for CO compared to $\mathrm{Pt}(111)^{29}$ (and $\mathrm{Rh}^{30}$ ). This factor alone should promote the cleavage of a possible $\left(\mathrm{CO}_{2}\right) 2^{\delta-}$ intermediate on $\mathrm{K} / \mathrm{Pt}, \mathrm{K} / \mathrm{Ni}$ and $\mathrm{K} / \mathrm{Rh}$ by lowering the free energy of the products. It might be interesting in this regard to conduct measurements for the more reactive metals at lower temperature so as to stabilize the intermediate and to compare the HREELS 
spectral characteristics with those observed on $\mathrm{K} / \mathrm{Ag}(111)$.

\section{E. CONCLUSIONS}

The results obtained in this investigation concerning the adsorption of $\mathrm{CO}_{2}$ on $\mathrm{K}$-modified $\mathrm{Ag}(111)$ surfaces are summarized as follows:

i) The TPD spectra of near saturation coverages of $\mathrm{CO}_{2}$ on $\mathrm{K} / \mathrm{Ag}(111)$, with $0.13<\theta_{K}<0.47$, (closed packed monolayer corresponds to $\theta_{K}=1 / 3$ ), display (in the absence of water and oxygen) a sharply defined $\mathrm{m} / \mathrm{e}=44$ peak at 796 $+/-6 \mathrm{~K}$ with no evidence for the presence of $C 0$ desorption peaks at any temperature. This behavior is unlike that found for other K-modified singlecrystal metal surfaces for which $C O$ is invariably observed in the TPD spectra.

ii) TPD experiments involving mixtures of natural and $18_{0}$ isotopically labelled $\mathrm{CO}_{2}$ indicate that scrambling of the oxygen atoms occurs and suggest that $\mathrm{CO}_{2}$ undergoes association on the $\mathrm{K} / \mathrm{Ag}(111)$ surface.

iii) The HREELS spectra of $\mathrm{CO}_{2}$-saturated $\mathrm{K} / \mathrm{Ag}(111)$ yield, in addition to very minor features, a single sharp peak at about $1480 \mathrm{~cm}^{-1}$. The XPS spectra of the same interface have a $C(1 s)$ peak with a binding energy of about 284 $\mathrm{eV}$, and thus as low as that observed for $\mathrm{CO}$ adsorbed on various $\mathrm{K}$-modified metals.

iv) Adventitious water or oxygen in the chamber and/or defect sites in the $\mathrm{Ag}(111)$ crystal gives rises to an additional $\mathrm{m} / \mathrm{e}=44 \mathrm{TPD}$ peak at much higher temperatures. The height of this new peak increases significantly by predosing the $\mathrm{K} / \mathrm{Ag}(111)$ surface with $\mathrm{O}_{2}$ or $\mathrm{H}_{2} \mathrm{O}$ at coverages as low as 0.05 L. The XPS spectra for these contaminated surfaces revealed features very different than those observed in the absence of such impurities, but consistent with the presence of an ordinary form of carbonate.

On the basis of these results, it is proposed that the dominant form of 
adsorbed $\mathrm{CO}_{2}$ on $\mathrm{K} / \mathrm{Ag}(111$ ) binds through the carbon to the surface to form some type of oligomer consisting of fragments with spectroscopic properties essentially identical to those of adsorbed $C O$ on alkali-metal modified surfaces linked by the other oxygen atom in $\mathrm{CO}_{2}$. Unlike isolated $\mathrm{O}($ ads) the reactivity of such bridging 0 towards $\mathrm{CO}_{2}$ is drastically reduced, due to a stabilizing effect of the neighboring $\mathrm{CO}$ (ads) and therefore does not generate a conventional type of carbonate such as that associated with peak $\beta$ for which the desorption temperature is much higher. Instead, the adsorbed 0 atom from partially dissociated $\mathrm{CO}_{2}$ recombines with neighboring $\mathrm{CO}$ (ads) to yield $\mathrm{CO}_{2}$ as the thermal-desorption product.

\section{F. SUGGESTIONS FOR FURTHER WORK}

The results obtained in this study indicate that, under most experimental conditions, carbon dioxide, present as an impurity in propylene carbonate will react with lithium (and other alkali and alkaline earth metals as well) to form the corresponding inorganic carbonates. Since it is not known whether this reaction adversely affects the performance of lithium electrodes, new strategies must be developed for examining in detail the reactivity of $\mathrm{PC}$ with lithium in the absence of carbon dioxide. One possible approach (which may be easily implemented in this laboratory) involves the use of a gold-coated cold finger for in-situ purification of PC. PC will be admitted into the chamber with the cold finger at $77 \mathrm{~K}$ with the bare $\mathrm{Ag}$ substrate at room temperature. Several monolayers of PC will be allowed to condense on the cold finger (the melting point of $\mathrm{CO}_{2}$ is much lower than 77 $K$ and therefore will not condense on the cold finger). After the chamber is pumped down to UHV, the alkali metal will be deposited on the Ag substrate. The latter will then be turned to face the cold finger. On warming the cold finger, clean PC should evaporate onto the alkali-metal surface and normal surface analysis could proceed. AES, XPS and TPD will be used to investigate 
the reactivity of $\mathrm{PC}$ with $\mathrm{Li}$ as a function of temperature.

The same approach can be used to assemble $\mathrm{PC} / \mathrm{Li}$ inierfaces for studies involving UHV/FTIR. It is expected that electron- and photon-based techniques will make it possible to gain a better understanding of the factors that control the chemical reactivity of $\mathrm{Li}$ toward non-aqueous solvents, and provide further insights into the structural and compositional factors that govern the transport of lithium in passive films of relevance to battery applications.

\section{G. REFERENCES}

1. For a series of articles on lithium electrodes see: "Lithium Batteries", Gabano, J. P., Ed., Academic Press, New York (1983).

2. Peled, E. J. Electrochem. Soc., 1981, 126, 357.

3. Thevenin J.; Muller, R. J. Electrochem. Soc., 1987, 134, 273.

4. Catalytic Activation of Carbon Dioxide, ACS Symposium Series, American Chemical Society, Washington, DC, 1988.

5. Solymosi, F.; Berko, A. J. Catal., 1986, 101, 458.

6. Solymosi, F.; Bugyi, L. J. Chem. Soc., Faraday Trans. I 1987, 83, 2015.

7. Liu, Z. M.; Zhou, Y.; Solymosi F.; White, J. M. J. Phys. Chem. 1989, 93, 4384 .

8. Liu, Z. M.; Zhou, Y.; Solymosi F.; White, J. M. Surface Sci. 1991, 245 , 289 .

9. Wohlrab, S.; Ehrlich, D.; Wambach, J.; Kuhlenbeck, H.; Freund, H.-J. Surface Sci. 1989, 220, 243.

10. a. Rodriguez, J. A.; Clendening, W. D.; Campbell, J. M.; Wu, M. ; Campbe11, C. T. J. Vac. Sci. Technol. 1989, 7, 2118. b. Rodriguez, J. A.; Clendening, W. D. ; Campbe11, C. T. J. Phys. Chem. 1989, 93, 5238.

11. Wang, K.; Eppe11, S. J.; Chottiner, G. S.; Scherson, D. A. (submitted Rev. Sci. Instr. January 1992)

12. Wagner, F. T.; Moylan, T. E. J. Electrochem. Soc. 1989, 136, 2498.

13. Garfunke1, E. L.; Somorjai, G. A. Surface. Sci. 1982, 115, 441.

14. Matsushima, T. J. Phys. Chem. 1987, 91, 6192. 
15. Phi Handbook, Perkin-Elmer Corp., Physical Electronics Division, 1977.

16. Blass, P. M.; Zhou, X.-L.; White, J. M. Surface Sci. 1989, $215,74$.

17. Argile, C.; Rhead, G. E. Surface Sci. 1988, 203, 175.

18. Blass, P. M.; Zhou, X.-L.; White, J. M. J. Vac. Sci. Technol. 1988, A7, 2009.

19. Handbook of Chemistry and Physics, Weast, R. C. Ed.; CRC Press, Cleveland OH, 1976.

20. Roop, B.; Blass, P. M.; Zhou, X.-L.; White, J. M. J. Chem. Phys. 1989, 90,608 .

21. Campbe11, C. T. Surface Sci. 1985, 157, 43.

22. a. Bonzel, H. P. Surface Sci. Rep. 1988,8 .

b. See also, Heskett, D.; Plummer, E. W. Phys. Rev. B 1986, 33, 2322.

23. dePaola, R. A. Hrbek, J.; Hoffman, F. M. J. Chem. Phys. 1985, 82, 2484.

24. Nakamoto, K. Infrared and Raman Spectra of Inorganic Compounds; Wiley: New York, 1987.

25. Stuve, E.; Madix, R. J.; Sexton, B. A. Chem. Phys. Letters 1982, 89, 48.

26. Madix, R. J.; Solomon, J. L.; Stohr, J. Surface Science 1988, 197, L253.

27. Wambach, J.; Odoerfer, G.; Freund, H.-J.; Kuhlenbeck, H.; Neumann, M. Surface Sci. 1989, 209, 159.

28. Yamada, T.; Tamaru, K. Surface Sci. 1984, 138, L155.

29. Froitzheim, H. ; Hopster, H.; Ibach, H.; Lehwald, S. App. Phys. 1977, 13, 147.

30. Thiel, P. A.; Williams, E. D.; Yates, J. T.; Weinberg, W. H. Surface Sci. 1979, 84, 54. 
ISOTOPIC COMPOSITION OF CARBON DIOXIDE MIXTURES BEFORE ADSORPTION AND AFTER ADSORPTION AND SUBSEQUENT THERMAL DESORPTION FROM $\mathrm{K} / \mathrm{Ag}(111)$ SURFACES FOR THREE INITIAL COMPOSITIONS

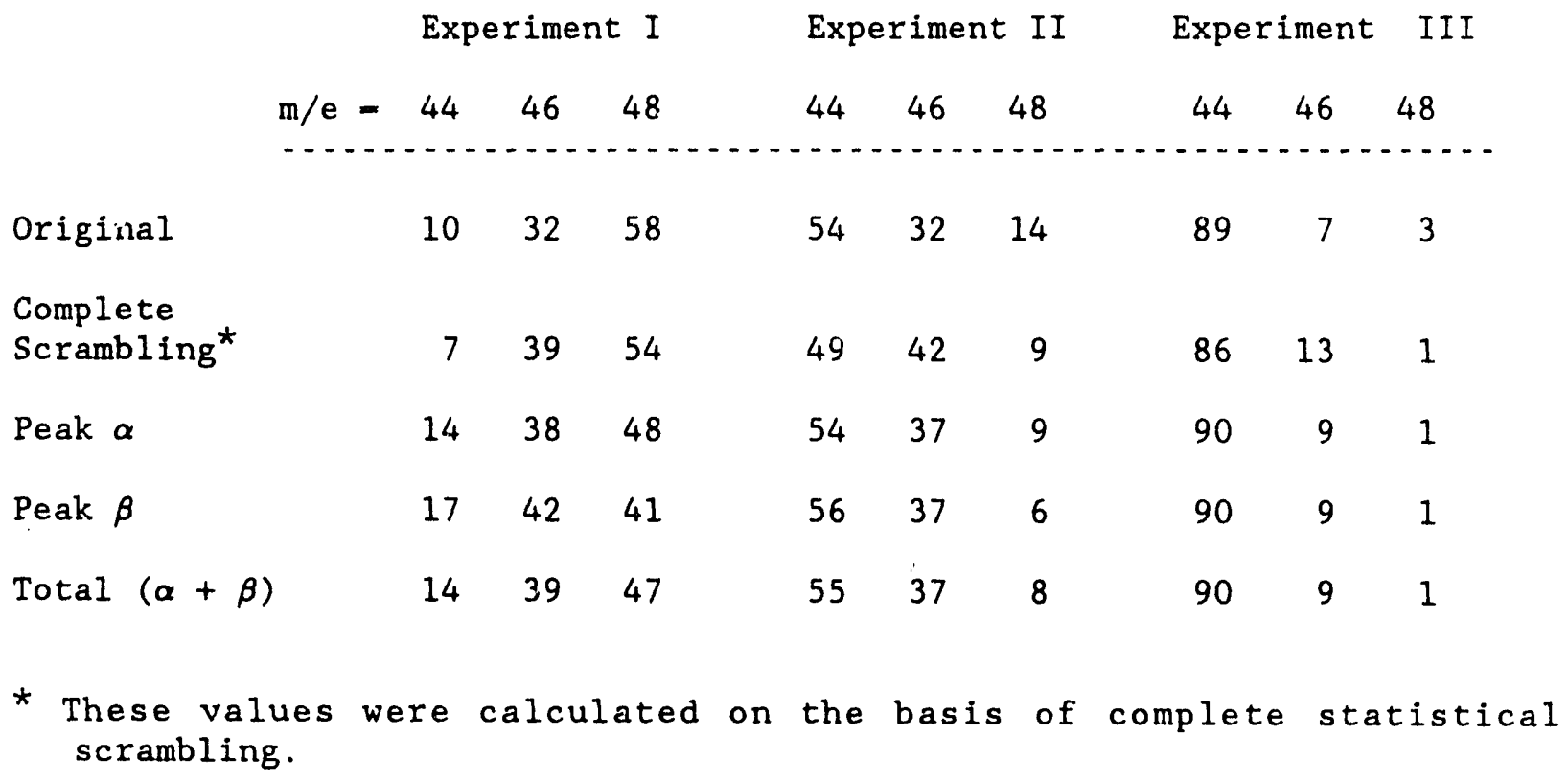




\section{H. FIGURE CAPTIONS}

Fig. 1. AES spectra of a contaminant-free $K\left(\theta_{K}=0.6\right) / A g(111)$ surface. Beam Voltage: $3 \mathrm{kV}$. Modulation Voltage: $3.7 \mathrm{~V}$ peak-to-peak. $\mathrm{K}$ was deposited from a SAES Getters source (see text for details).

Fig. 2. Surface concentration of $\mathrm{K}$ on $\mathrm{Ag}(111)$ obtained from $\mathrm{AES}$ (see text) versus sample temperature as the specimen is heated. The break at about 208 indicates a coverage of about 1 monolayer.

Fig. 3. $\mathrm{CO}_{2}$ (Curve $\mathrm{A}$ ), $\mathrm{O}_{2}$ (Curve $\mathrm{B}$ ) and $\mathrm{CO}$ (Curve C) TPD spectra of $\mathrm{CO}_{2}$ saturated $K\left(\theta_{K}=1 / 3\right) / A g(111)$ surface. $K$ was deposited with the $\mathrm{Ag}(111)$ specimen at about $220 \mathrm{~K}$. AES spectra were recorded prior to $\mathrm{CO}_{2}$ exposure.

Fig. 4. Work function change $\Delta \Phi$ in $\mathrm{eV}$ (solid line) and integrated area under the $\mathrm{CO}_{2}(\mathrm{~m} / \mathrm{e}-44)$ peaks in the TPD spectra (solid circles) of $\mathrm{K}\left(\theta_{\mathrm{K}}=1 / 3\right) / \mathrm{Ag}(111)$ surface versus $\mathrm{CO}_{2}$ exposure in Langmuirs.

Fig. 5. TPD spectra of $\mathrm{K}\left(\theta_{\mathrm{K}}-1 / 3\right) / \mathrm{Ag}(111)$ exposed to $\mathrm{CO}_{2}$ immediately after $\mathrm{K}$ deposition at $220 \mathrm{~K}$ (Curve $\mathrm{A}$ ). Curve $\mathrm{B}$ shows the results obtained in similar experiments in which $\mathrm{K}$ is characterized with LEED and AES prior to $\mathrm{CO}_{2}$ exposure.

Fig. 6. Peak temperature of $\mathrm{CO}_{2}$ TPD peak versus $\mathrm{K}$ coverage for $\mathrm{K} / \mathrm{Ag}(111)$ surfaces saturated with $\mathrm{CO}_{2}$.

Fig. 7. TPD spectra for $\mathrm{m} / \mathrm{e}=44,32,28,18$ from experiments in which $1 \mathrm{~L}$ of water was adsorbed on $\mathrm{K}\left(\theta_{\mathrm{K}}=1 / 3\right) / \mathrm{Ag}(111)$ before $\mathrm{CO}_{2}$ adsorption,

Fig. 8. TPD of naturally abundant $\mathrm{CO}_{2}(\mathrm{~m} / \mathrm{e}=44)$ (solid line) and ${ }^{13} \mathrm{CO}_{2}$ $(\mathrm{m} / \mathrm{e}=45)$ (dashed line) after exposure of a $\mathrm{K}\left(\theta_{\mathrm{K}}=1 / 3\right) / \mathrm{Ag}(111)$ to an equimolar mixture of (naturally abundant) $\mathrm{CO}_{2}$ and ${ }^{13} \mathrm{Co}$.

Fig. 9. TPD spectra from experiments in which $K\left(\theta_{K}=1 / 3\right) / \mathrm{Ag}(111)$ was exposed to $0.5 \mathrm{~L}$ of dioxygen prior to $\mathrm{CO}_{2}$ adsorption. 
Fig. 10. C(1s) (left panel) and $O(1 s)$ (right panel) XPS(ESCA) spectra of $\mathrm{K}\left(\theta_{\mathrm{K}}=1 / 3\right) / \mathrm{Ag}(111)$ (bare), exposed to saturation coverage $\mathrm{CO}_{2}$, (A, 1 and 2), and pre-exposed to $0.35 \mathrm{~L}$ of $\mathrm{O}_{2}(\mathrm{~B}, 1$ and 2 ) and pre-exposed to 1 L of water (C, 1 and 2) prior to saturation exposure $\mathrm{CO}_{2}$. The satellite contributions (at the energies shown by arrows in the figure) were not subtracted from the measured spectra. For all of these experiments, the dosings were performed at 223 and the spectra were recorded at $263 \mathrm{~K}$.

Fig. 11. HREELS spectra of $\mathrm{K}\left(\theta_{\mathrm{K}}=0.13\right) / \mathrm{Ag}(111)$ plus saturation $\mathrm{CO}_{2}$ (see text for details). Both $\mathrm{K}$ deposition and $\mathrm{CO}_{2}$ dosing were performed at ca. $290 \mathrm{~K}$.

Fig. 12. $m / e=28$ and 44 TPD spectra from a $K\left(\theta_{K}=1 / 3\right) / A g(111)$ surface which had been damaged by repeated heating prior to $\mathrm{K}$ deposition and saturation exposure $\mathrm{CO}_{2}$ (see text for details).

Fig. 13. Schematic diagram of proposed $\mathrm{CO}_{2}$ oligomeric species. Solid lines represent $\mathrm{C}-\mathrm{O}$ bonds subtending a small rather than a large angle with respect to the surface normal. Dashed lines denote $C-O$ bonds mostly parallel to the surface which may involve through-metal interactions as opposed to clear chemical bonds. 


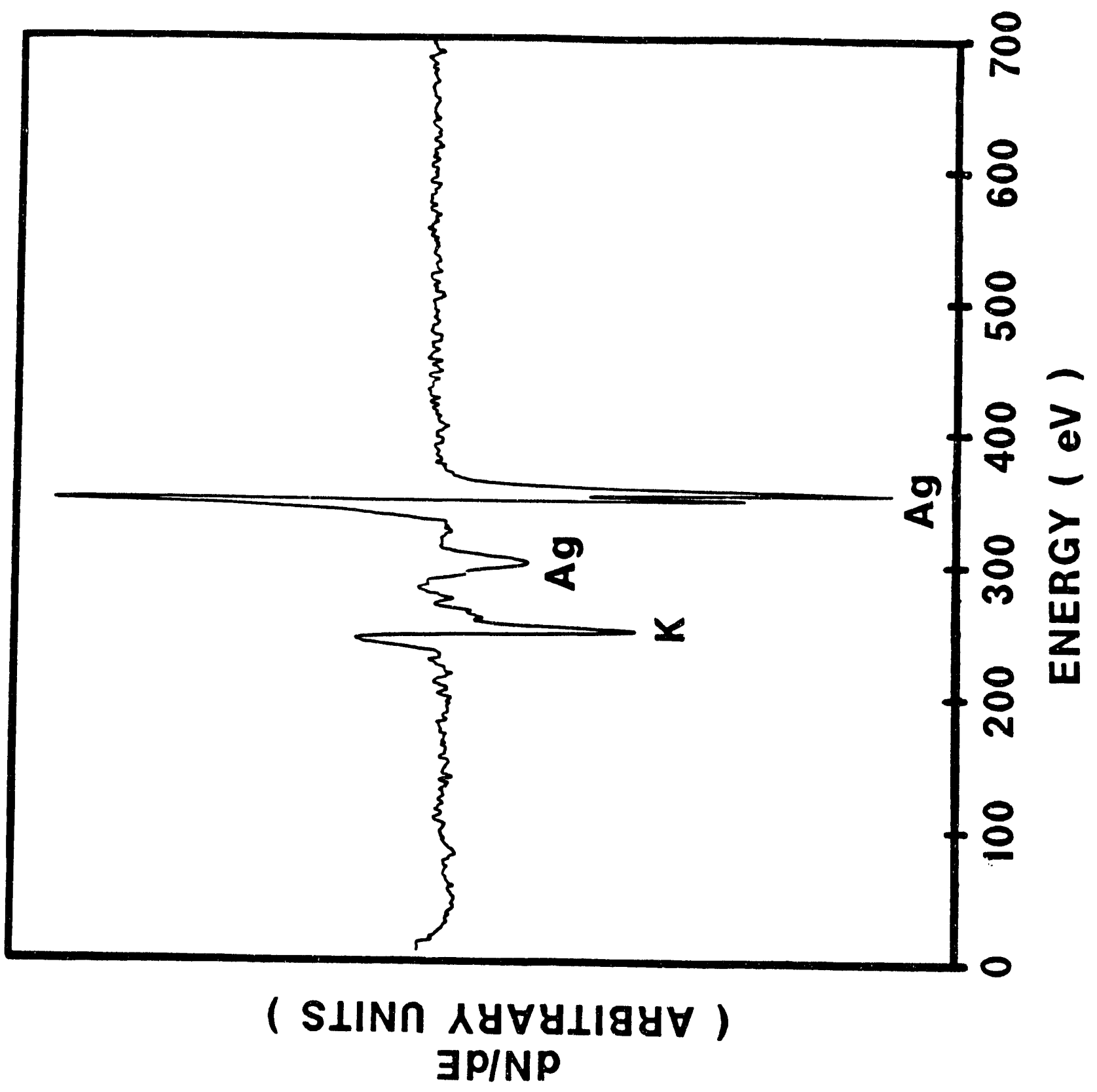

Figure 1 


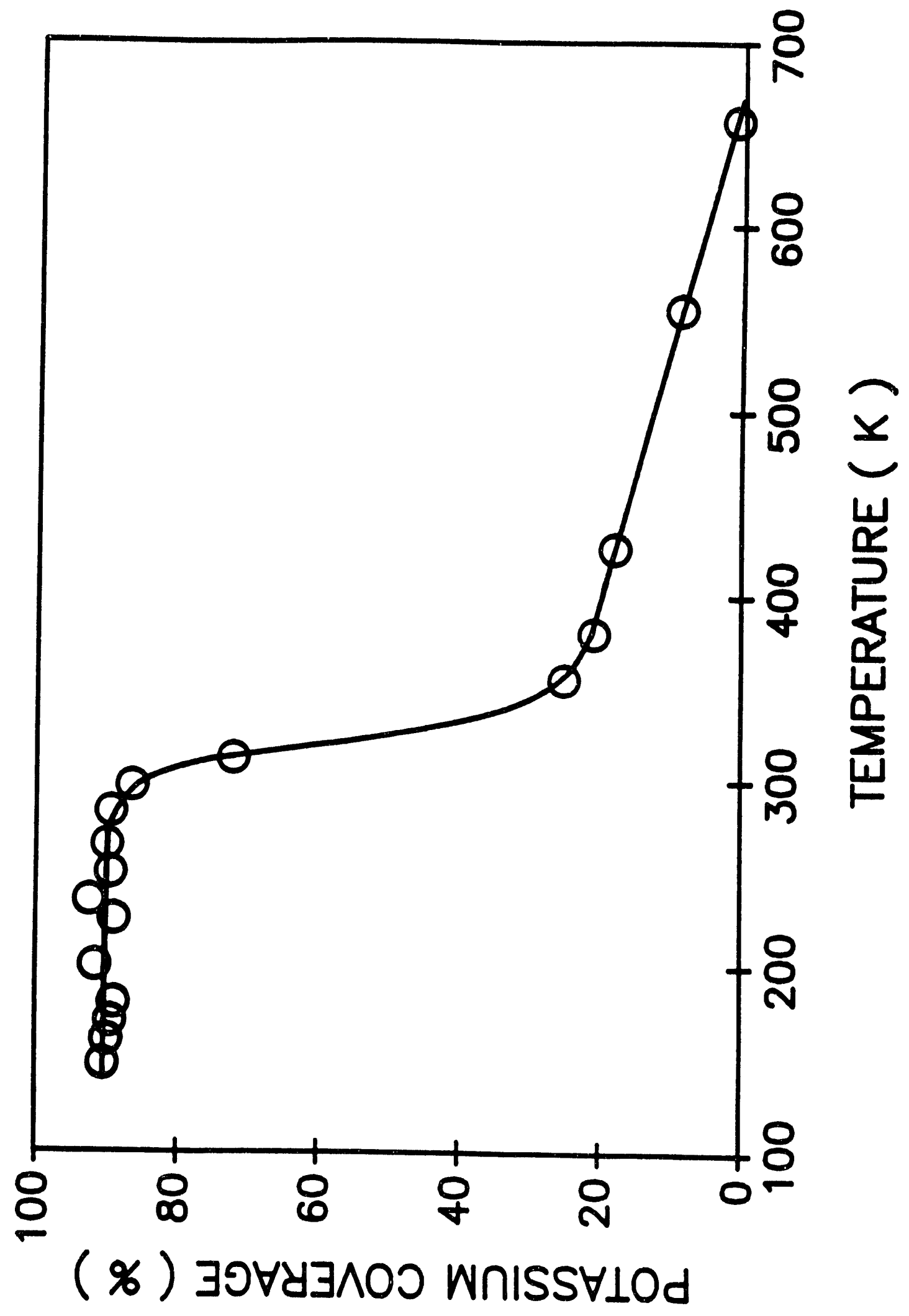

Figure 2 


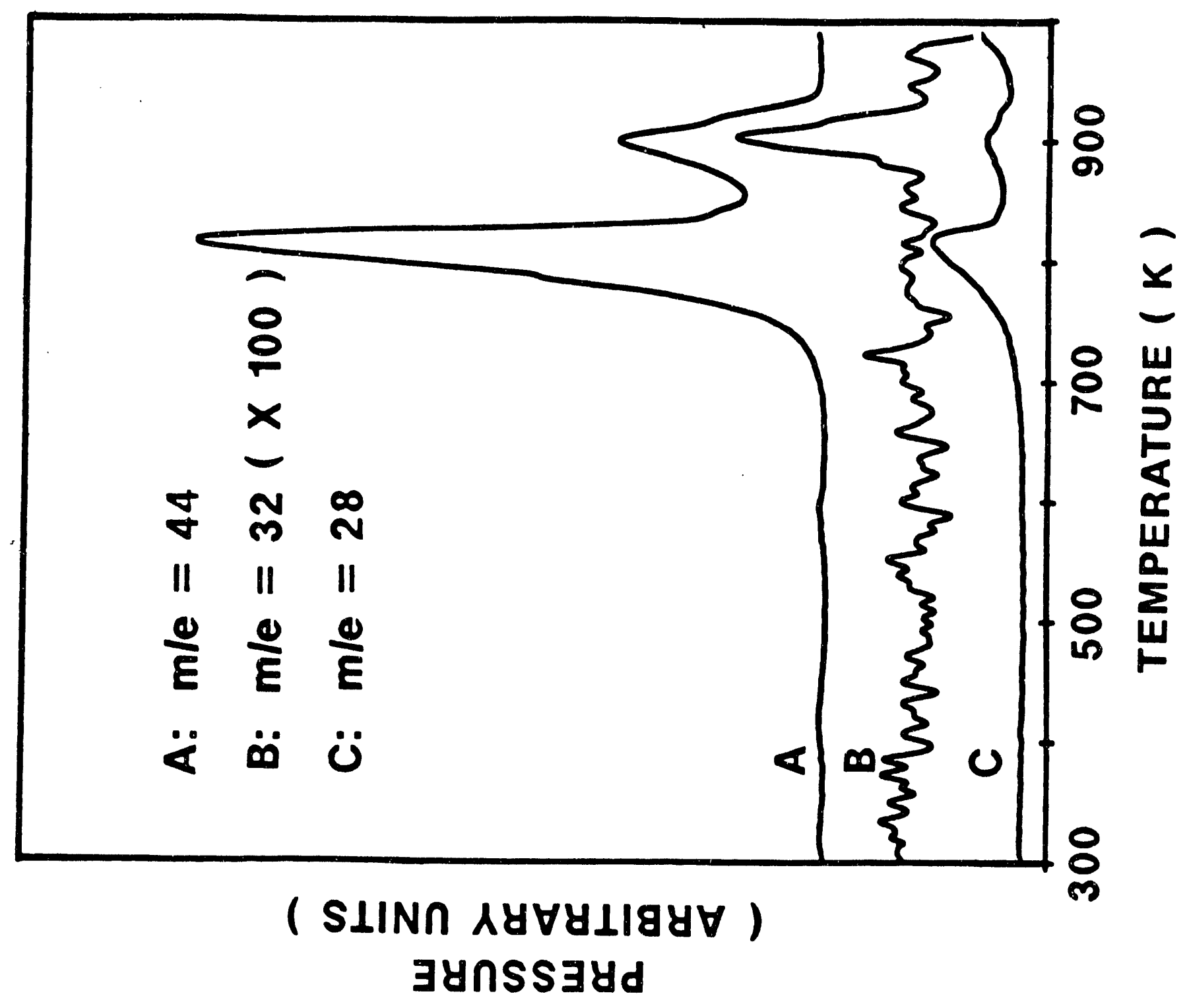

Figure 3 


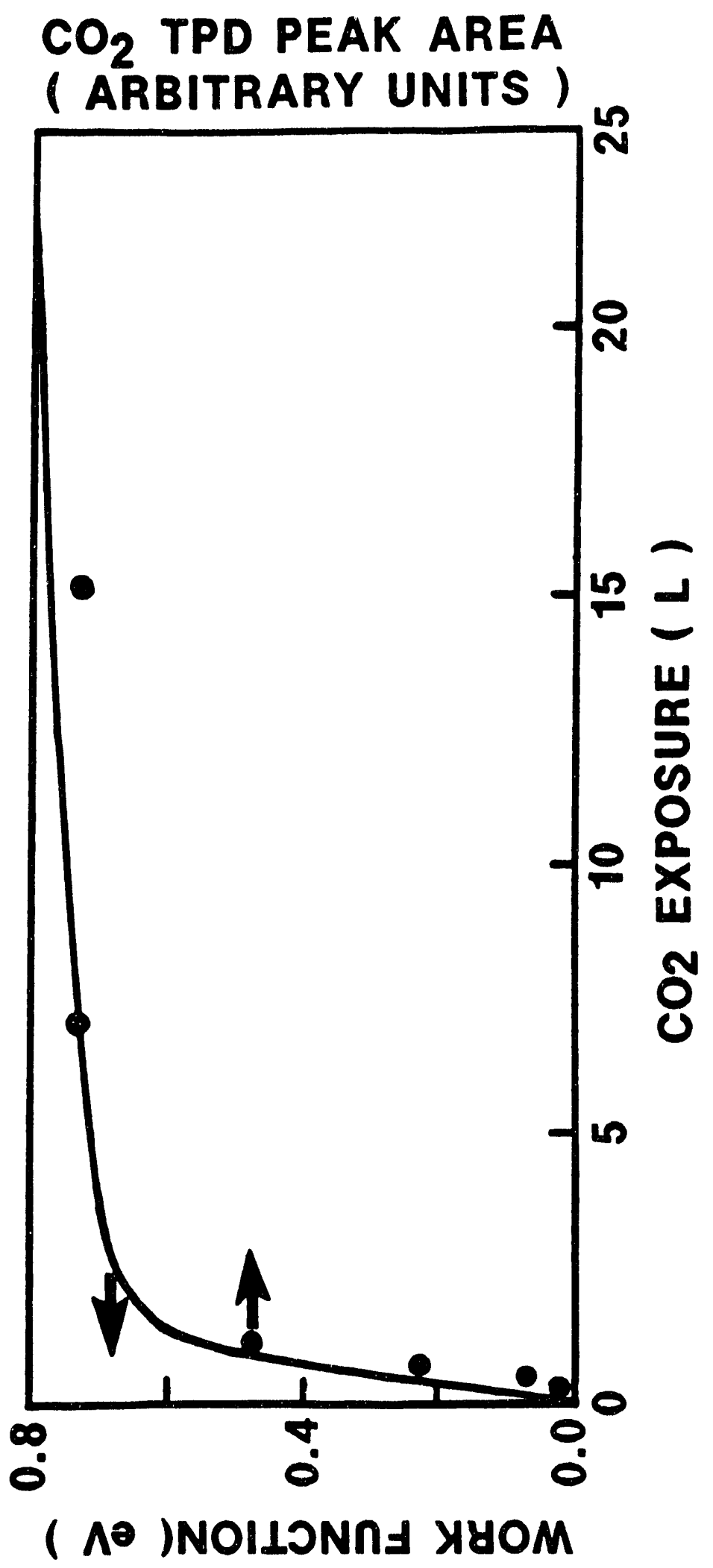

Figure 4 


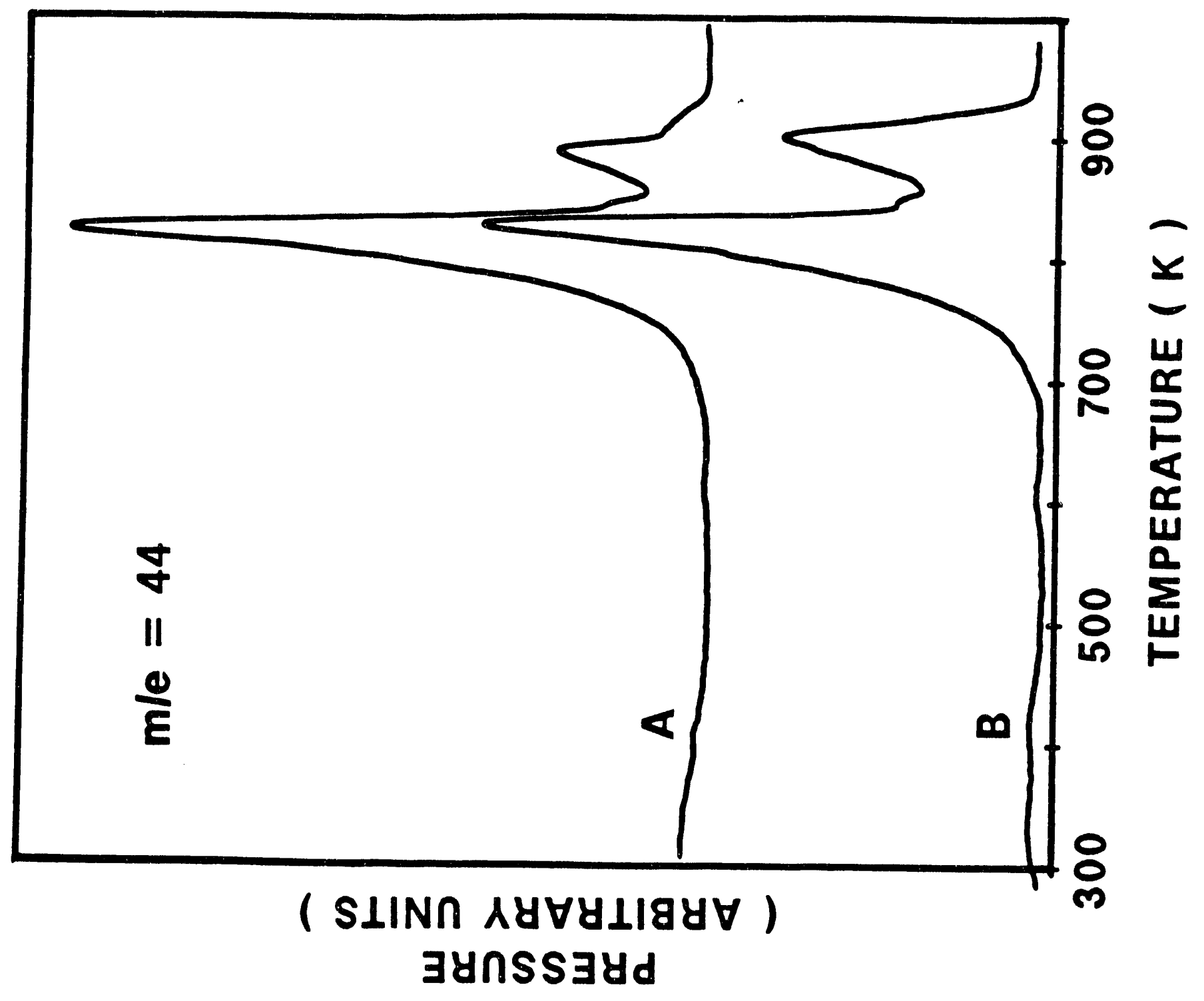

Figure 5 


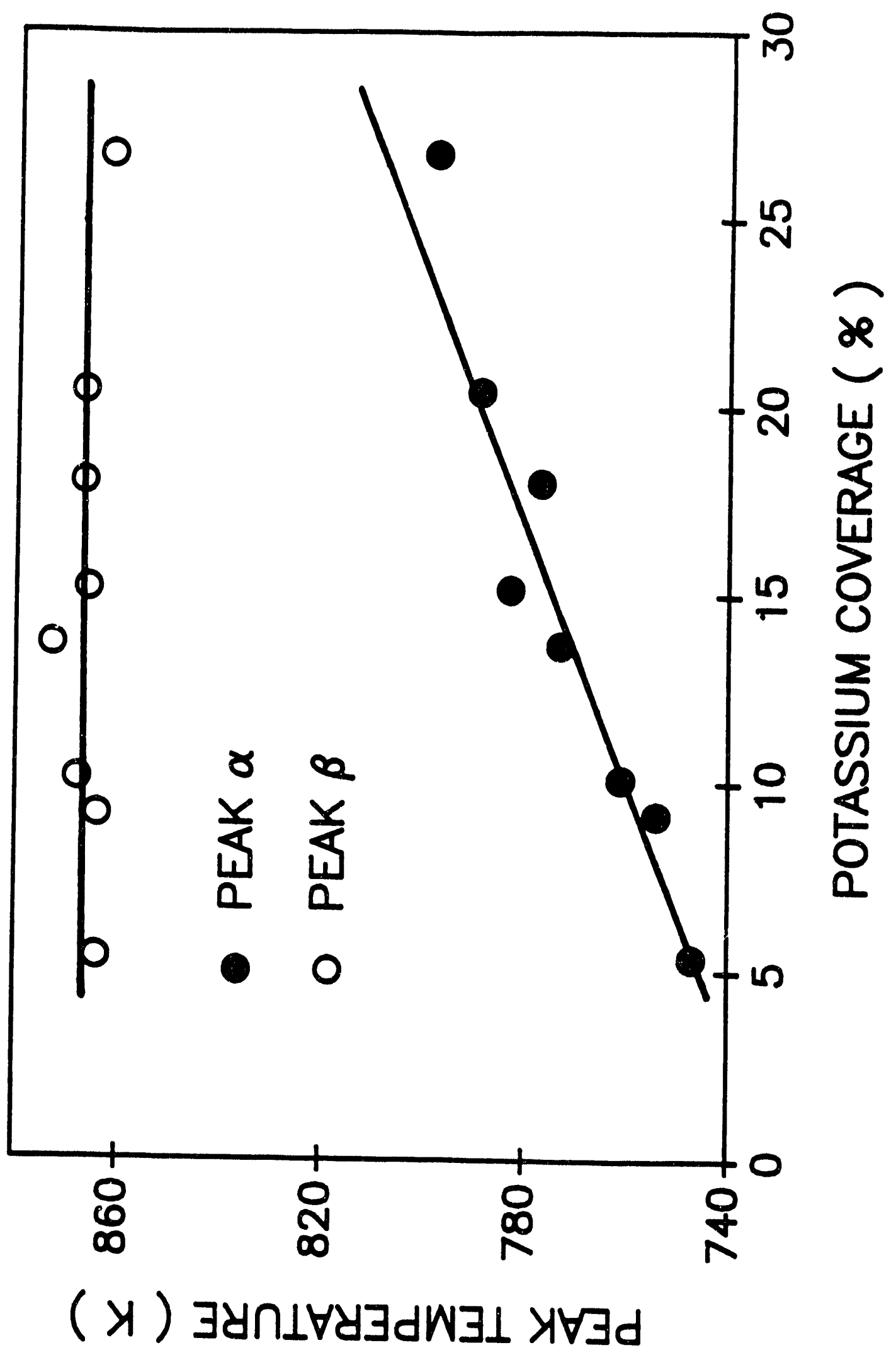

Figure 6 


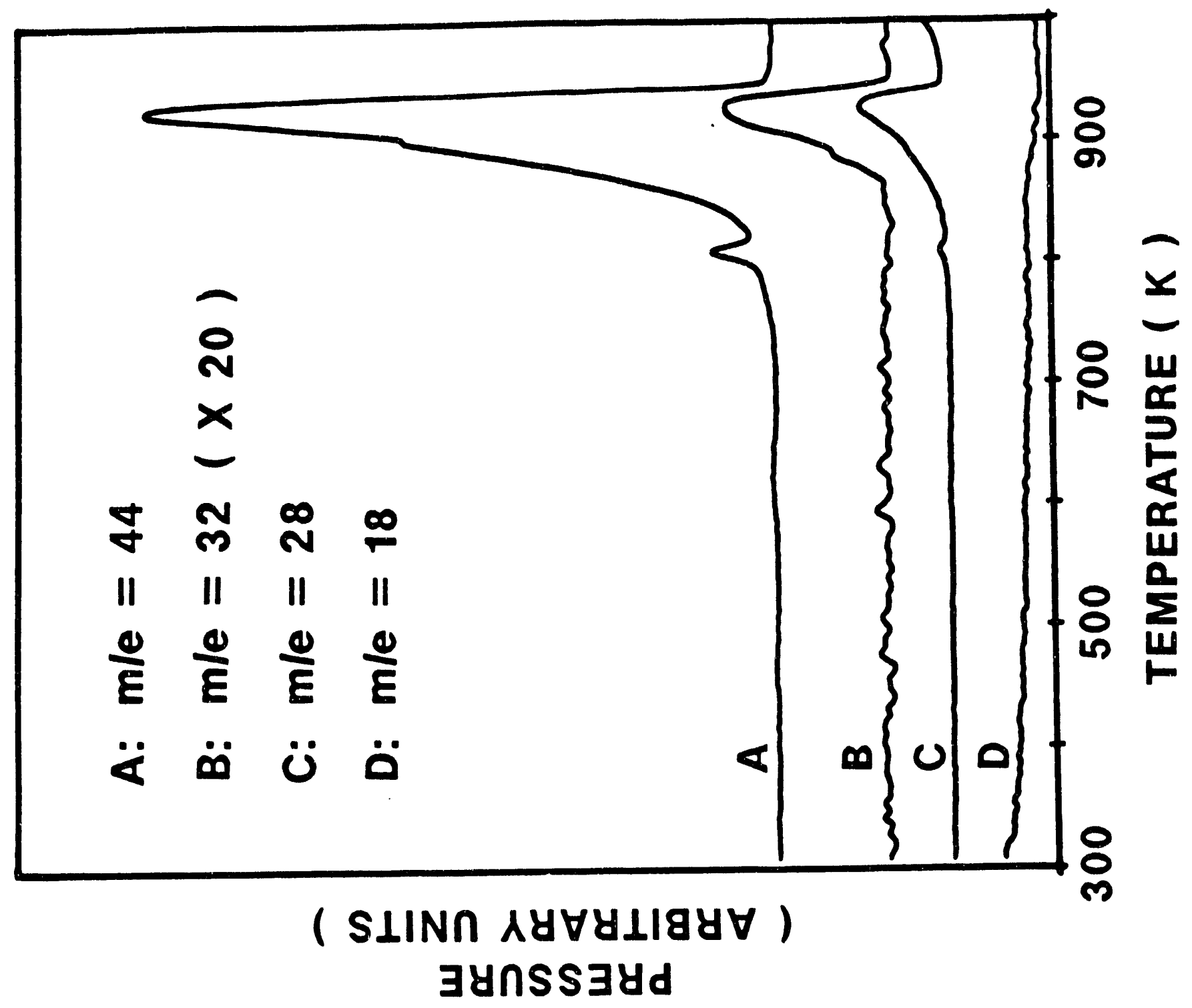

Figure 7 


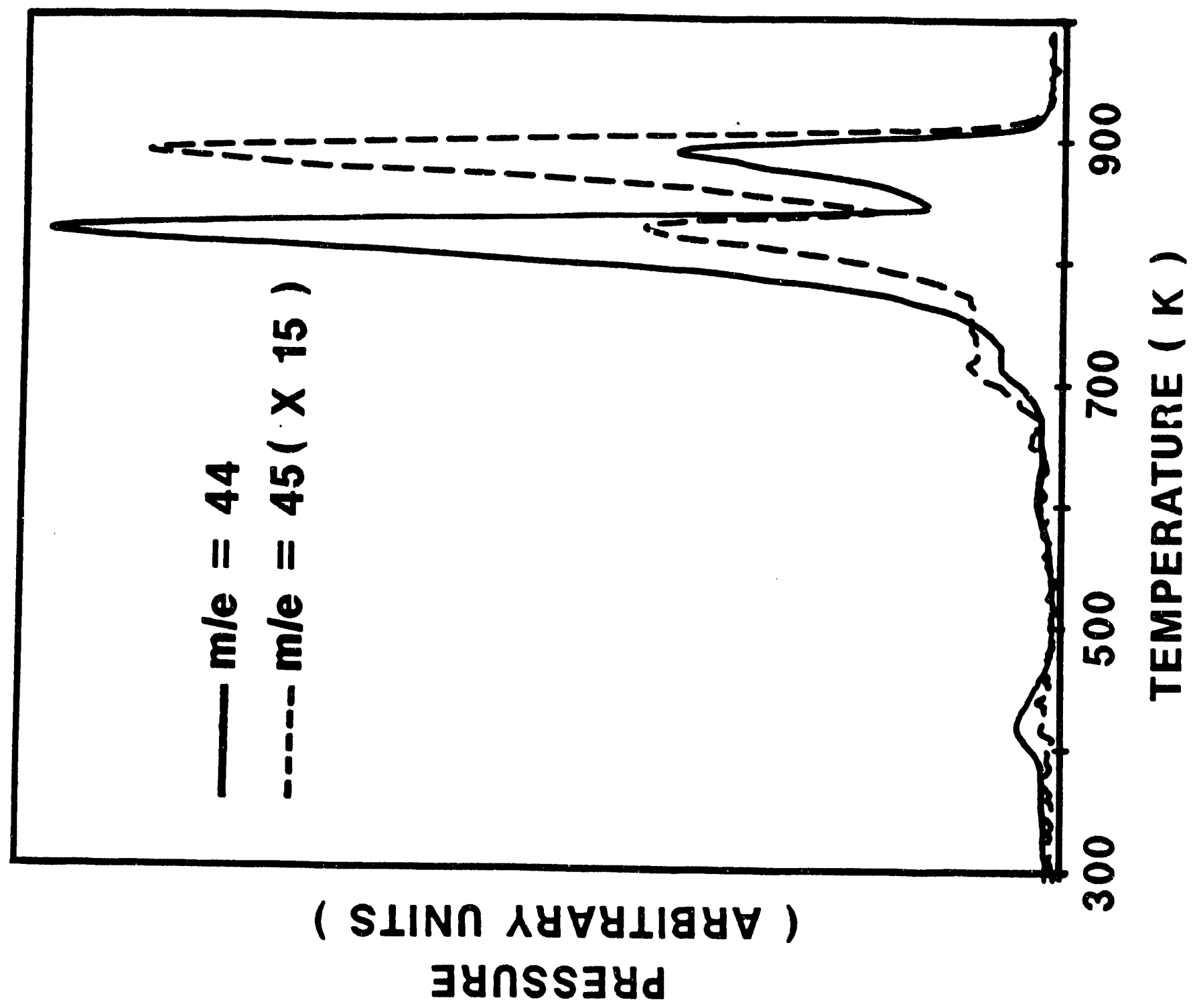

Figure 8 


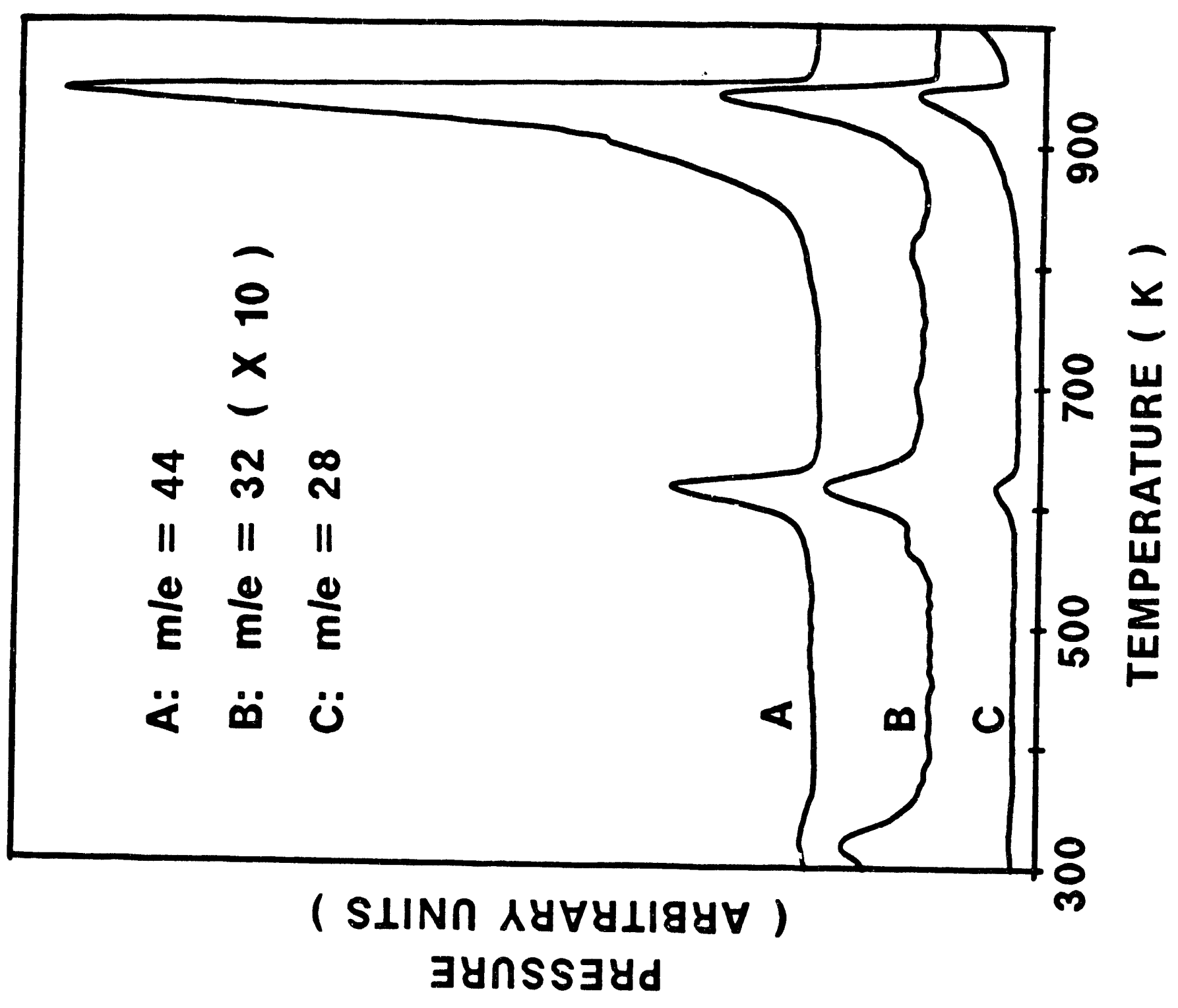

Figure 9 


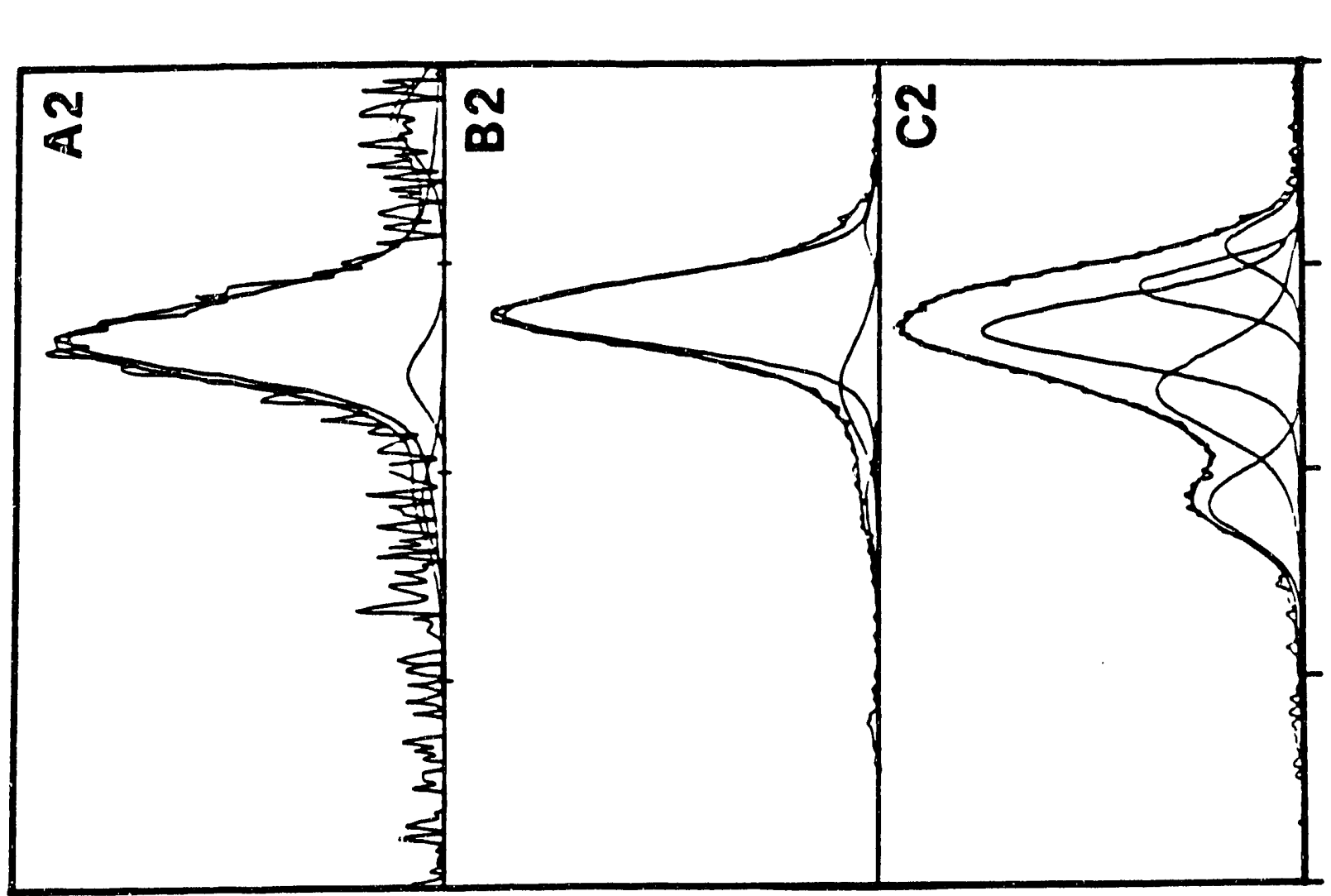

I

10

ח

i 2

120

$\pi$

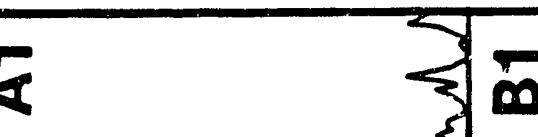

$\infty \quad \sum \sqrt{6}$
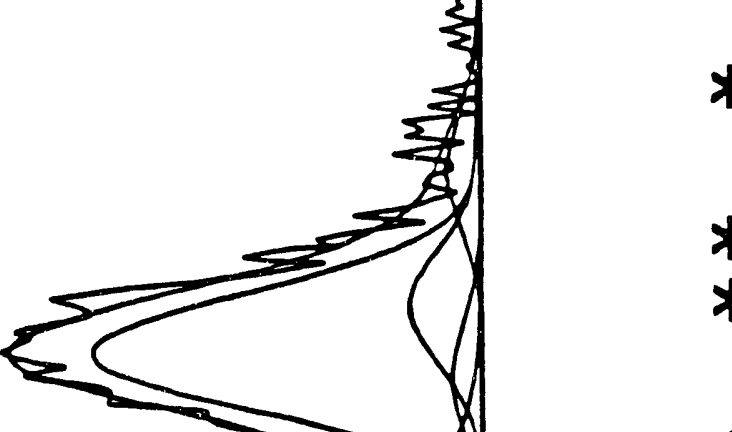

$x$

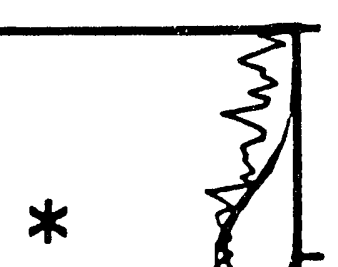

$\infty$

11

N

U1

$\frac{2}{2}$
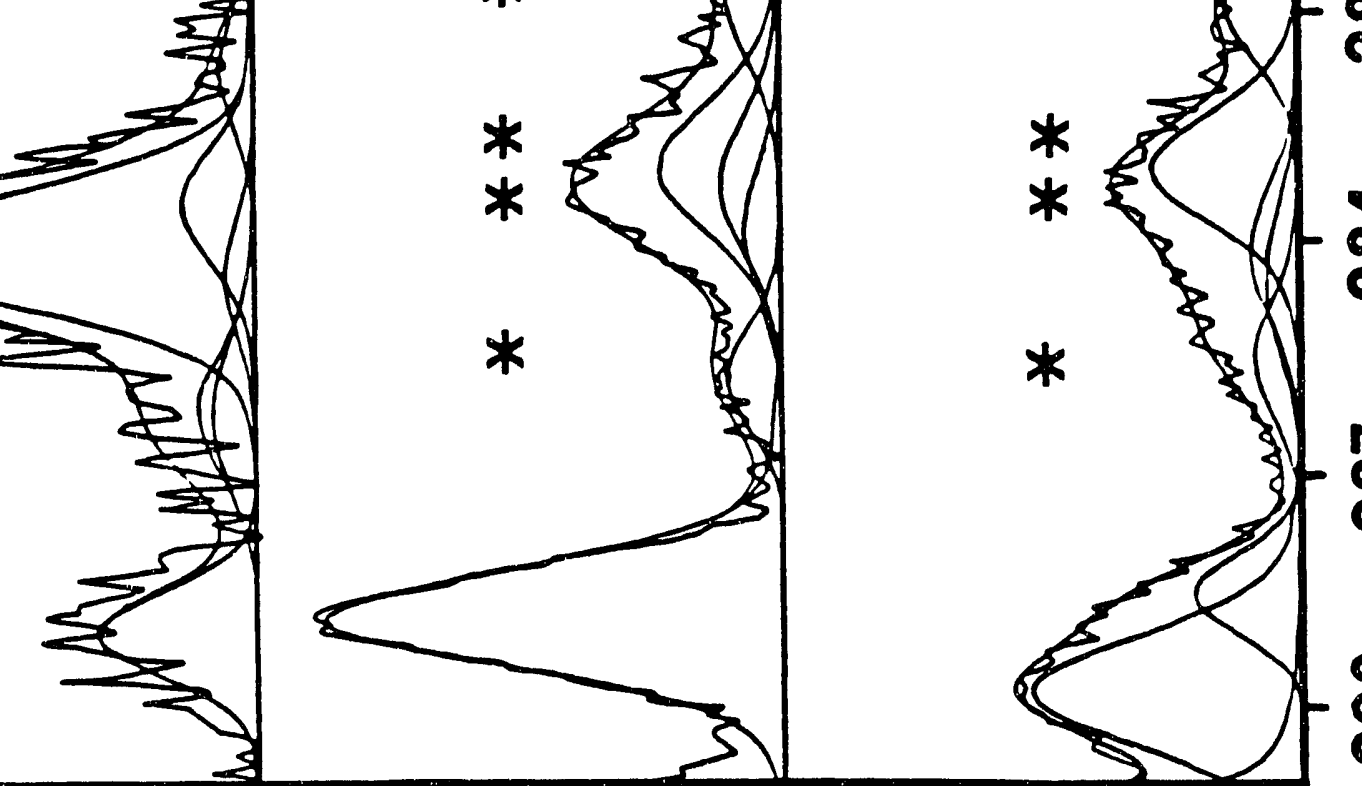

$\infty$

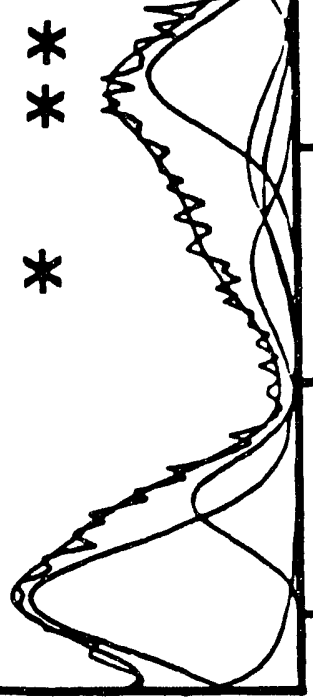

$\infty$

N

$\infty$

$\boldsymbol{N}$

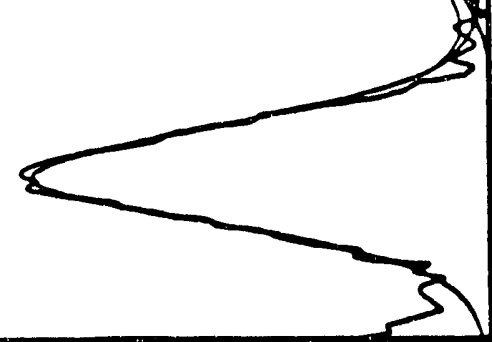

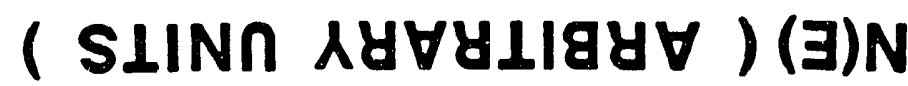

Figure 10 


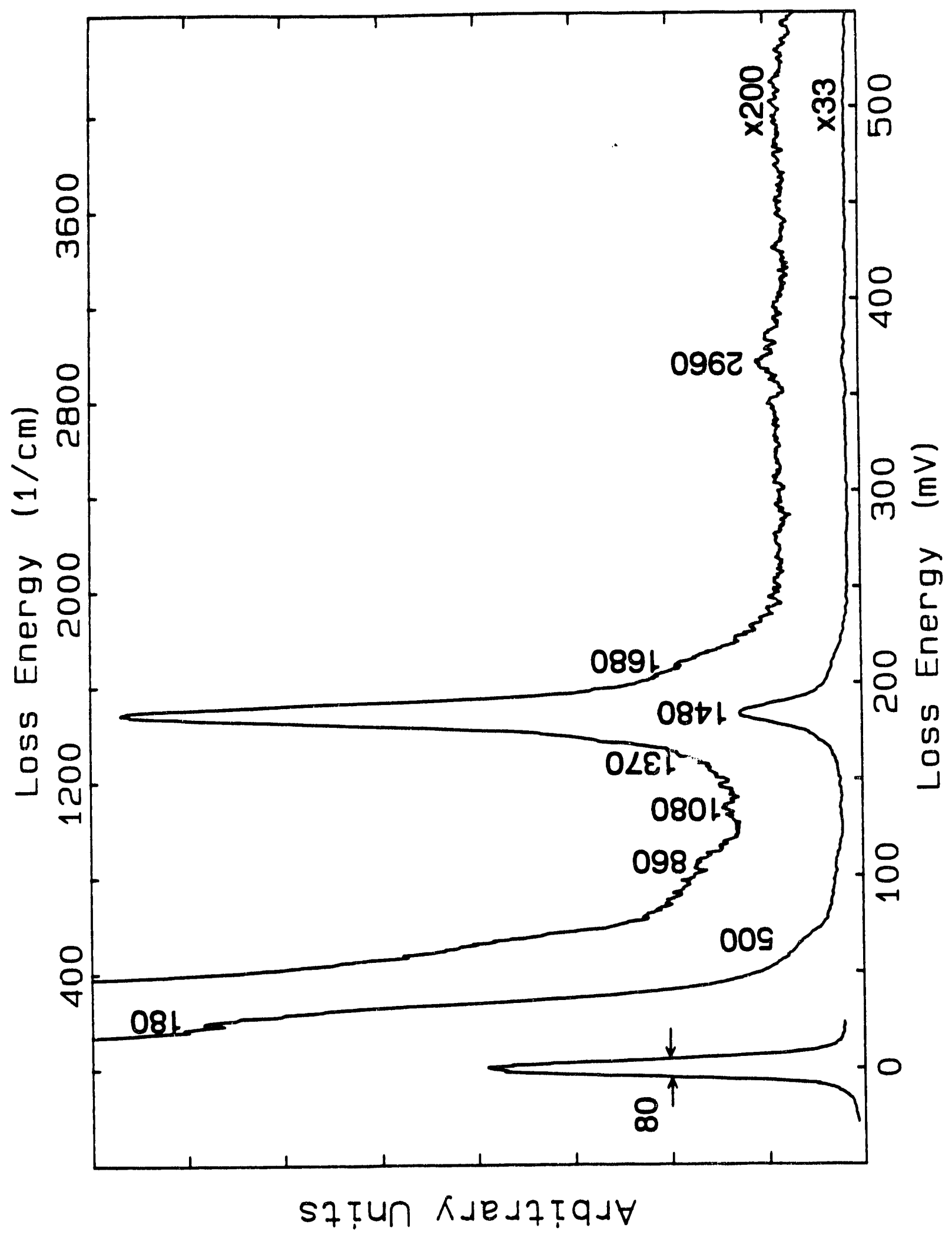

Figure 11 


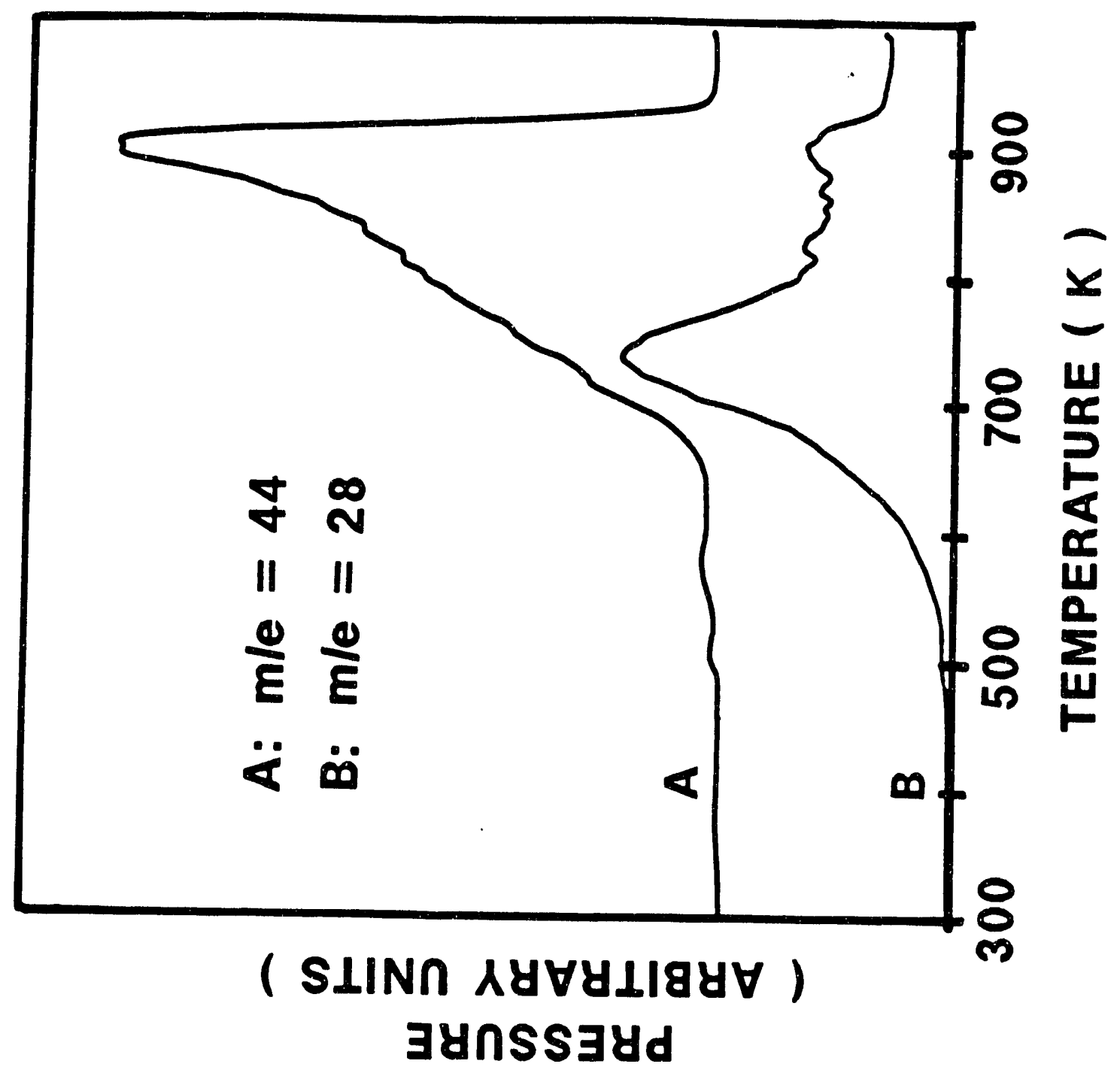

Figure 12 


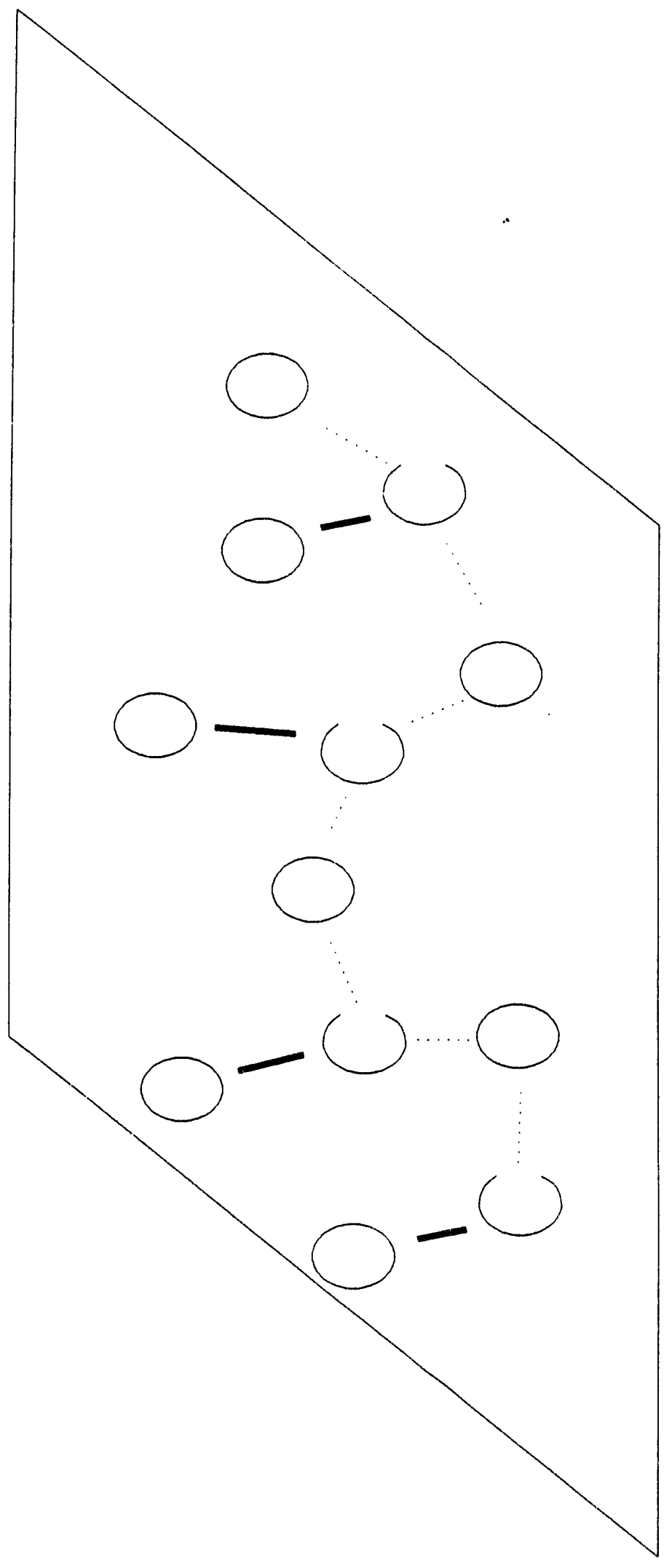

Figure 13 

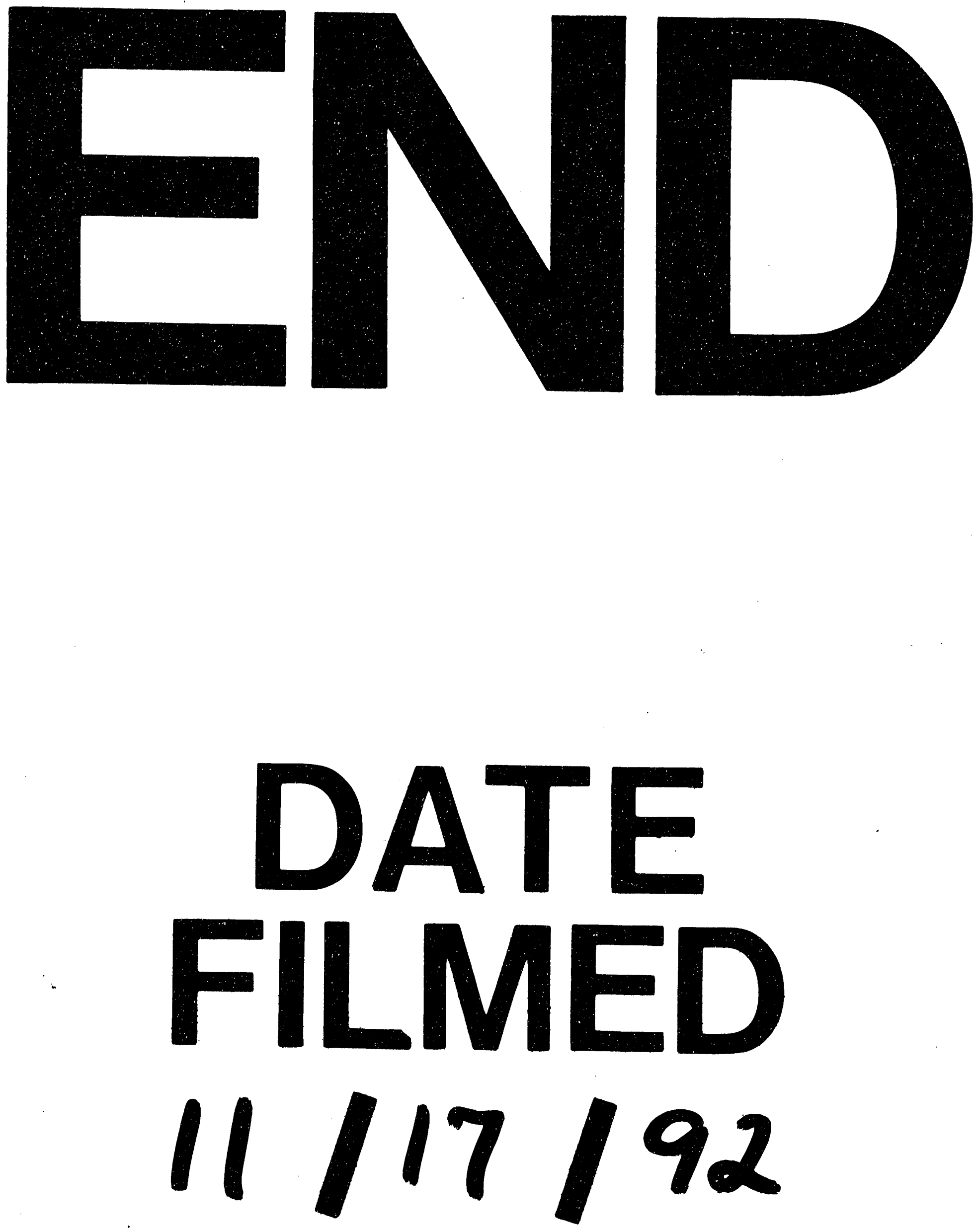
